\title{
LA PREDICCIÓN EN SISTEMAS COMPLEJOS: CIENCIA Y APLICACIÓN PRÁCTICA
}

\author{
Froilán Sevilla Martínez
}

Servicio Territorial de Medio Ambiente de Burgos. Junta de Castilla y León. Pza. Bilbao 3. 09006BURGOS (España). Correo electrónico: sevmarfr@jcyl.es

\section{Resumen}

En el último medio siglo se ha desarrollado una línea epistemológica que ha influido en disciplinas científicas tan variadas como la meteorología, la economía o la medicina, y que podríamos denominar estudio de sistemas complejos, o teoría del caos en su expresión matemática. Los ecosistemas forestales podrían considerarse el arquetipo de sistemas complejos: están compuestos por elementos (subsistemas) que son a su vez complejos; son heterogéneos en tiempo y espacio, a todas las escalas; presentan propiedades emergentes en función de la escala; tienen dependencia sensitiva a las condiciones iniciales; etc. La predicción en sistemas complejos nunca es completamente precisa pero existen tácticas para ir acotando las incertidumbres. La inclusión de aspectos socioeconómicos en la investigación resultaría en una aproximación más fructífera en la predicción ecológica. Los paradigmas forestales, la ciencia y la técnica se deben adaptar al cambio radical de situación socioeconómica y ecológica provocada por el fin del sistema agrario tradicional hace ya medio siglo: de la prioridad original en la defensa, y después en la restauración, ha llegado el momento de convertir a los aprovechamientos en el principal instrumento para conseguir objetivos de gestión, que engloban los de conservación de especies y ecosistemas. La ciencia ecológica debe asumir la complejidad para ser realista y servir a la gestión, pero es a la vez necesaria la búsqueda de la simplicidad en la toma de decisiones. Existen en la actualidad conocimientos suficientes para predecir con alta probabilidad las líneas generales de la respuesta del ecosistema a las acciones o a la pasividad. En cada lugar concreto, la técnica del ensayo (bien planificado y dirigido) y error (evaluado), ayuda a perfilar los detalles predictivos. Una capacidad de predicción mejorada debería posibilitar una gestión más anticipadora que sirva para prevenir procesos indeseados y para el cumplimiento de los objetivos fijados: ir a remolque de las dinámicas espontáneas es una opción mediocre para lograr el cumplimiento de los objetivos que, de forma no muy bien articulada, nos impone la sociedad.

Palabras clave: Sistemas caóticos, Prognosis, Incertidumbre, Paradigmas, Eventos renovadores, Gestión anticipadora

\section{INTRODUCCIÓN}

El sector forestal español se encuentra en la actualidad en una encrucijada. El drástico cambio en las dinámicas ecológicas, fruto del fin del sistema agrario tradicional hace medio siglo, exige un replanteamiento general del papel de los fores- tales. El fundamento de su existencia es su aptitud para diseñar e implementar acciones que ayuden a cumplir los objetivos que se establezcan para los montes. Para lograrlo su base de conocimiento es la ecología, que debería concebirse desde un enfoque prioritariamente holístico, integrador. La complejidad de los ecosistemas fores- 
tales hace de la prognosis en ellos una ciencia siempre en continua mutación, pero que debe partir de una sólida base epistemológica menos cambiante. El mundo conceptual de los sistemas complejos parece un marco adecuado para ese desarrollo científico y técnico, por haber probado en otras disciplinas del estudio de la naturaleza, como la meteorología, su capacidad para mejorar las predicciones.

La excesiva separación entre científicos y gestores es motivo de preocupación y muestra de que algo profundo falla en la organización forestal española. La moderna ciencia ecológica proporciona un marco conceptual que debería ayudar a superar esa desconexión, en la medida que es más realista, más preocupada por los procesos y menos por la obsesión de encajar a la naturaleza en patrones preconcebidos, independientes de las circunstancias concretas.

\section{DETERMINISMO E INCERTIDUMBRE. SISTEMAS CAÓTICOS. SISTEMAS HISTÓRICOS}

Los ecosistemas forestales reúnen una serie de atributos propios de sistemas que clasificamos como complejos:

- Gran cantidad de elementos constituyentes, de variados tipos, tanto vivos como inanimados. Los organismos vivos se pueden agrupar en especies, cada una con sus propios atributos vitales y comportamientos. Pero incluso cada individuo presenta unas características únicas que lo distinguen de otros de la misma especie, con diferencias unas veces sutiles pero otras de gran calado.

- Sistemas abiertos, con evidentes conexiones con otros sistemas.

- Dependencia de sistemas que ya están catalogados como complejos, como el climático (donde ya hace medio siglo se mostraron comportamientos caóticos -LORENZ, 1963-) o las sociedades humanas.

- Relaciones de variado tipo entre los componentes (competencia, predación, facilitación, etc.), cambiantes en espacio y tiempo.

- Medio heterogéneo a todas las escalas.

- Sistemas históricos, es decir, que se configuran por una compleja sucesión de aconteci- mientos pasados. En ocasiones, pequeñas variaciones en las condiciones iniciales o en la forma de desarrollarse los procesos generan cambios trascendentales y duraderos. La propiedad se denomina dependencia sensitiva.

- Propiedades que sólo resultan evidentes a determinadas escalas.

- Relaciones y series temporales no lineales. Mecanismos de retroalimentación. Propiedades fractales. Etc.

La visión de muchos organismos interactuando unos con otros y con el medio según sus propias habilidades, definidas por sus atributos vitales, parece mucho más realista que la de fraccionar la realidad en cajones (lechos de Procusto), en especial si se comete el exceso de nombrarlos (en latín), como se hace en las asociaciones vegetales. Desde luego la dinámica forestal no está constreñida a unas "series de vegetación", pero tampoco es cierto que todo pueda ocurrir: existen algunos "principios de imposibilidad", que en general más bien son límites muy difíciles de franquear. Estos límites están motivados por restricciones de tipo físico y no, obviamente, por relaciones florísticas: la afinidad interespecífica indica una preferencia por unas condiciones de desarrollo semejantes, y en ciertos casos simbiosis (en bosques tropicales son muy frecuentes) o facilitación. Esas condiciones recogen el efecto del medio geoclimático y de la historia previa, aspecto este último que se obvia con asiduidad. Estudiar las relaciones de afinidad es muy importante, porque la reunión de ciertas especies en un lugar nos ayuda a entender rasgos esenciales de la organización del ecosistema; pero nunca se debería sustituir lo que es un indicio (la afinidad) por lo decisivo, que es el conocimiento de las capacidades de cada especie o cada individuo, pues son las que definen su relación con otros seres vivos y en definitiva su papel en el ecosistema. En esta visión más individualista, hay todo un gradiente de probabilidades de que algo suceda, y en sus extremos algunas situaciones o procesos no pueden existir, mientras otros es casi seguro que se van a dar. El camino de ir acotando las opciones posibles y de identificar las más probables es la esencia de la predicción ecológica.

Los condicionantes de tipo físico que en última instancia operan son con frecuencia muy difí- 
ciles de establecer y caen en el campo de la fisiología. La precisa composición y organización de las células y tejidos de las plantas decide sus posibilidades de rebrotar, resistir incendios, crecer en climas áridos o soportar una espesa sombra: la observación de estos rasgos es la base para efectuar predicciones ecológicas, aunque se desconozcan las bases fisiológicas. De particular importancia dinámica, y quizá insuficientemente valorado, resulta el atributo de la tolerancia a la concurrencia, que evalúa de forma sintética las posibilidades que tiene de desarrollarse una planta en concurrencia de otras.

Será difícil mejorar sustancialmente la capacidad de predicción ecológica si no se asumen plenamente los postulados característicos de los sistemas complejos. No es lo mismo introducir la complejidad en la base epistemológica que hacer más complicados los métodos y la presentación de resultados de aproximaciones simplistas en su base. En realidad esta segunda opción es contraproducente. Hasta cierto punto esto es lo que ha ocurrido con los estudios sintaxonómicos: es correcto establecer relaciones de afinidad entre taxones, pero cuando se pretende dotarlas de un significado dinámico o funcional, es necesario añadir otros tipos de análisis, es decir, introducirse en el mundo epistemológico de los sistemas complejos; pero no sirve con hacer cada vez aproximaciones más complejas, siguiendo el camino reduccionista, complicando el mundo conceptual de las asociaciones para intentar adaptarse a una realidad con la que se difiere marcadamente (ver RIVAS-MARTínEZ, 2011). La idea original de Braun-Blanquet, que se limita a constatar la relativa proximidad o repulsión en la distribución de individuos de las diferentes especies, tenía una claridad que se ha ido perdiendo cada vez que se ha pretendido encajar a la naturaleza en cajones mejor delimitados, lo que para MARGALEF (1991) envenenó el mensaje original de la fitosociología, y la hizo más ininteligible y menos práctica. Se debe intentar seguir exactamente el camino contrario: asumir en los postulados básicos que se trata de sistemas complejos y organizar el conocimiento de la manera más simple posible, con un lenguaje accesible y unos modelos que nunca se alejen de la realidad tal y como se observa directamente (o por sensores remotos).
La visión ontológica de los ecosistemas que nos proporciona la sintaxonomía es tan cómoda para los que la creen como poco científica. Lo cierto es que nada o casi nada está predeterminado en los montes, y que la precisa cadena histórica de acontecimientos ocurridos es la que finalmente determina con precisión su composición y estructura. José Sebastián Carrión, en una revisión de múltiples trabajos paleoecológicos, concluyó en 2003: "Con los conocimientos actuales, la contingencia histórica aparece como un poderoso responsable del tempo y modo de la trayectoria vegetal. Podría ocurrir también que el azar aparente no fuera azar en definitiva, sino más bien un aspecto del fenómeno denominado caos. Hay pistas: a poco que penetremos con cierto detalle en una secuencia vegetal multimilenaria nos encontramos con interacciones múltiples, multitud de pautas irrepetidas y una extraordinaria sensibilidad a la situación inicial. Y cuanto más profundizamos, menos plausibles se hacen las explicaciones mecanicistas. El mundo lineal constituye una parte muy importante de nuestra existencia. Sin embargo, la mayor parte de la naturaleza no es lineal y no puede predecirse con facilidad. Las tendencias que observamos parecen ejemplos de dinámica compleja que desafían la simulación o el análisis matemático convencional". Lo que ya empezaba a resultar evidente en la paleoecología española, sería deseable que se convirtiese en la "ciencia normal forestal".

Los montes no están determinados por "condiciones medias", ni del medio geoclimático, ni de eventos renovadores ("perturbaciones"). Eventos raros, que sólo sucedan una vez durante un milenio, pueden resultar decisivos, y evidentemente escapan a los habituales análisis estadísticos. Ejemplos de estos eventos infrecuentes con efectos de largo alcance pueden ser deforestaciones o incendios intensos en bosques muy húmedos. El hecho de que algunos individuos arbóreos (por ejemplo de Pinus nigra o Taxus baccata) vivan más de 1.000 años debería ser suficiente para convencerse de que las precisas condiciones que ocurrieran en el establecimiento de los pies, un milenio atrás, han tenido repercusiones transcurrido ese periodo. Y, por supuesto, lo que ocurre con los individuos lo hace en mayor medida con los ecosistemas, en 
los que las evidencias del efecto de eventos acontecidos milenios atrás siguen siendo decisivas en los montes actuales.

En España, la deforestación y en general el cambio global del ecosistema ocurrido durante la revolución neolítica, hace 6 milenios en muchas zonas del norte y algo más en el sur, todavía afecta a la composición y dinámica de los montes actuales, por ejemplo al haber eliminado algunas especies, tanto animales como vegetales, de amplias zonas o de la Península Ibérica en su conjunto. Las investigaciones paleoecológicas, ya muy bien desarrolladas en la Península Ibérica, dan innumerables ejemplos en este sentido (ver una magnífica recopilación en CARRIÓN, 2012). No requiere mayor argumentación el hecho de que cuando en un sistema desaparece una de las piezas esenciales (por ejemplo, un árbol dominante o un animal numeroso y de gran tamaño), cambia su funcionamiento.

Muchos modelos sobre los ecosistemas forestales ibéricos, sobre todo los basados en criterios sintaxonómicos, constituyen una "no-explicación", sólo útil para la "no-intervención", y en conjunto forman una "no-teoría" en el sentido de PeTERS (1991); esto es, un constructo intelectual que no sirve para realizar predicciones. Cuando prescriben "lo que debería haber en un lugar", prescindiendo de lo que en la actualidad hay en él, de su historia y de su contexto, suponen un exceso que es ajeno completamente a la utilidad de una "no-teoría". En realidad, las "no-teorías" son un instrumento importante de la ciencia, pero su función es diferente a las teorías y no deben

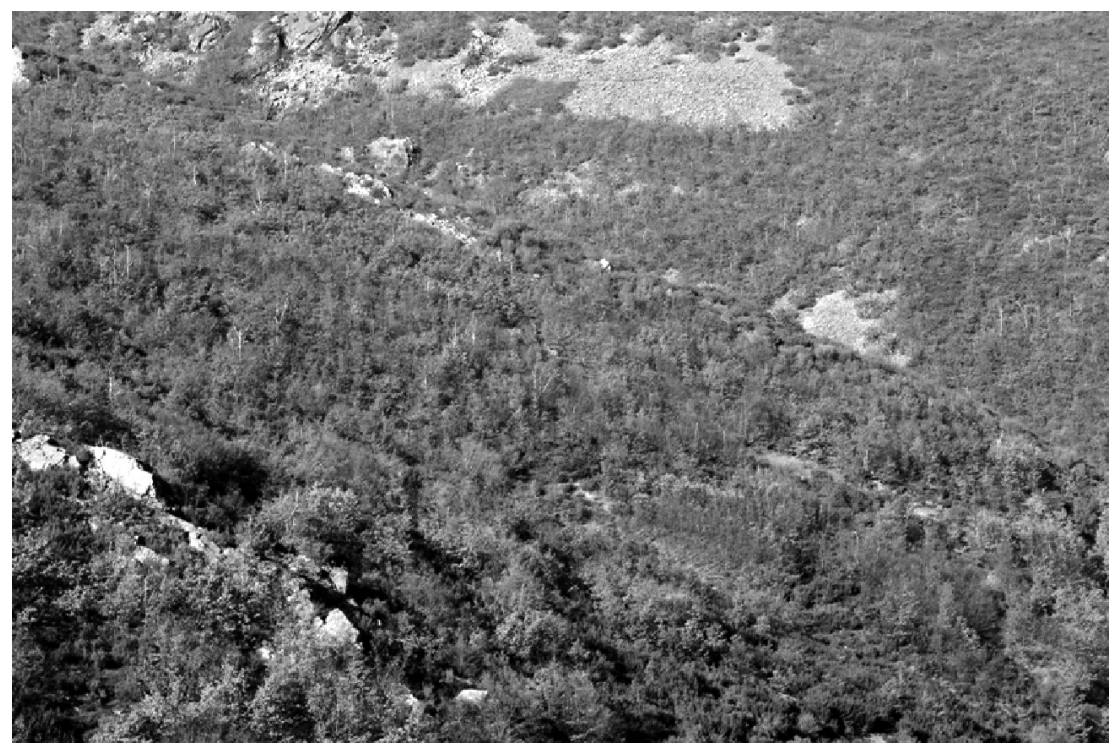

Figura 1. Paisaje de fuego, dominado por rebollos, brezos y algunos arbustos y matas leguminosos. Cada nuevo incendio favorece el subsiguiente, al rebajar la altura del arbolado y permitir la continuidad del matorral pirófito. Se aprecian los troncos quemados, todavía en pie, de la generación de rebollos que dominó antes de la renovación. Las especies no rebrotadoras, como los pinos, o las que lo hacen en escasa medida en comparación con el rebollo, como son muchas frondosas mesófilas, han desaparecido de estos montes hace siglos o milenios. Curiosamente, al tipo de vegetación presente, procedente de un manejo muy concreto que incluye eventos renovadores de gran intensidad, se le ha otorgado la categoría de climácica: se ha dado carta de naturaleza a los efectos de drásticas acciones humanas, simplemente por el prejuicio de considerar que lo tradicional conlleva una suerte de "bondad intrínseca". Los mismos prejuicios han llevado a justificar la eliminación de los pinos en base a cambios climáticos, a pesar de una relación causal mucho más evidente con el fuego utilizado por el hombre, y de que las cronologías climáticas y de supresión de los pinos no coinciden. Aquí el clima es suficientemente húmedo como para que vivan especies mesófilas capaces de eliminar completamente el brezo en la fase de expulsión: si se logra romper el ciclo de retroalimentación del fuego, con los modernos medios de extinción, éste se podría casi excluir del ecosistema, o convertirlo en irrelevante en la escala de las décadas, de forma que a medio plazo se daría una profunda transformación ecológica que incluiría dinámicas novedosas (Los Barrios de Gordón, León) 
confundirse con ellas so pena de que ambas no lleguen a desempeñar su papel (PETERS, 1991).

\section{INVESTIGACIÓN Y GESTIÓN FORESTAL EN ESPAÑA}

La primera constatación que es preciso exponer es que España no existe como país en el mundo forestal, incluyendo tanto la gestión como la investigación, entre otras muchas facetas: no presenta ningún tipo de unidad, y apenas coordinación, en las políticas ambientales y dentro de ellas en las forestales. Cada comunidad autónoma sigue su propio camino, que por otra parte en general carece de un rumbo bien marcado. $\mathrm{Ni}$ siquiera los mínimos legales que impone la normativa básica se respetan en todo el territorio nacional, y no sólo en preceptos difusos susceptibles de interpretación divergente, sino también en otros muy concretos y de tanta trascendencia para la gestión como por ejemplo la obligación de que exista un fondo de mejoras en los montes catalogados de utilidad pública (artículo 38 de la Ley 43/2003, de 21 de noviembre, de Montes).

El hecho de que el grado de descentralización de la gestión sea muy elevado no tendría por qué constituir un problema, más bien al contrario, al posibilitar una gestión más adaptada a las peculiaridades locales. Pero el papel del estado es clave en muchos aspectos. Es el interlocutor ante la Unión Europea, que deja libertad a sus miembros en política forestal pero que, por ejemplo, ha establecido el armazón normativo y supervisa la Red Natura 2000. Es necesario que el estado represente los intereses españoles en su conjunto, por mucho que éstos parezcan ser sumamente dispares cuando se analizan internamente, por regiones. Y debe ser el garante de una organización mínima que evite disfunciones. La realidad es que las dificultades son enormes para ejercer ese papel, en una España tan descentralizada y con una mentalidad individualista. Y el alejamiento de la Administración Central respecto de la realidad en el terreno no ayuda nada en esa ímproba tarea.

¿Por qué no se ha avanzado nada en el nexo entre gestión e investigación forestal en España en las últimas décadas? Básicamente porque no hay ningún estímulo real para que la investiga- ción sea realmente aplicable. Los programas en los que se integran los proyectos de universidades y centros de investigación responden a otras necesidades. En la actualidad, la publicación en revistas de impacto se ha convertido en el mecanismo fundamental para evaluar a los investigadores, y no la resolución de problemas reales o el número de patentes. Por su parte, los gestores están poco motivados para aplicar unos avances científicos que les resultan ajenos y demasiado teóricos. Quizá el mayor motivo para ser optimista en el futuro es que con un carácter creciente desde los ámbitos científicos se estudian más los procesos y se valoran con mayor escepticismo las posiciones apriorísticas; en un futuro cercano esta tendencia debería culminar en una aproximación más fructífera entre investigación y gestión.

Los forestales de campo tienen una posición privilegiada para hacer avanzar la ecología, dado que disponen del más completo laboratorio y del acicate de la necesidad de mejorar sus predicciones a las escalas de años y décadas, para lo cual pueden observar los efectos de sus intervenciones (o de su inactividad) en ecosistemas de diversa complejidad. Para hacer efectiva esa responsabilidad son necesarias grandes dotes de observación, fusión de variados tipos conocimientos y capacidad de síntesis. La combinación con investigadores que aporten ideas y sistematicen observaciones sería muy fructífera.

La aversión generalizada que exhiben colectivos no forestales hacia la intervención en el medio natural, o la utilización mal enfocada y contraproducente del principio de precaución, constituyen indicadores de que no han profundizado en la línea epistemológica de los sistemas complejos, en los que la incertidumbre está siempre presente. La afirmación complementaria de que por el hecho de actuar los forestales lo hayan logrado desde luego no es cierta. Aquí influye mucho la formación profesional y una orientación general hacia la actuación y la resolución inmediata de problemas en las ingenierías. El hecho de que los forestales hayan trabajado con mayor frecuencia en repoblaciones y rodales espontáneos coetáneos ha facilitado el establecimiento de relaciones causales y ha hecho más certera la prognosis: es mucho más sencillo extraer conclusiones en sistemas simples que en complejos; los montes son siempre complejos, 
pero si en una primera instancia se aborda el estudio de ecosistemas muy heterogéneos y con gran diversidad de especies dominantes, las complicaciones son abrumadoras y reducidas las posibilidades de acertar en las predicciones.

Cuando se implica a los científicos directamente en las decisiones de gestión, normalmente los resultados no son satisfactorios, y no sólo por el desconocimiento de los procesos operativos (implementación), sino fundamentalmente porque no se acotan, y se sobrevaloran, las inevitables incertidumbres: en sistemas complejos siempre hay que asumir que una parte de los factores se escapa al control, pero cuando la producción científica ha evolucionado sistemáticamente y durante largos periodos desligada de la gestión, es muy fácil que esa parte no incluida en los modelos sea excesivamente grande.

Existe una "tensión esencial" entre la necesidad de modelos complejos para explicar una realidad que también lo es (realismo) y el deseo de sencillez para hacer posible la conexión con la gestión.

\section{ECOLOGÍA Y ECONOMÍA}

La gestión de los montes debería ser una aplicación directa de la ecología forestal. Ésta a su vez debería englobar aspectos socioeconómicos para ser más directamente aplicable a la gestión.

Para intentar pasar de la simple concomitancia a la causalidad, por mucho que ésta se establezca de forma tosca, es imprescindible considerar y entender la influencia del hombre, de los factores socioeconómicos y culturales. Los ecosistemas son sistemas históricos, es decir, su configuración actual está motivada por una precisa concatenación de acontecimientos precedentes. Los ecosistemas se van configurando a lo largo de la historia por la acción de unos eventos renovadores de variadas características, actuando sobre situaciones de partida y medios geoclimáticos heterogéneos. La heterogeneidad incluye por supuesto un acervo genético territorializado. Si conocemos un poco de la historia forestal de España, es fácil admitir que los principales eventos renovadores, en los últimos milenios (desde la revolución neolítica), han llegado de la mano del hombre. Algo que en reali- dad es común a casi todo el planeta, excepto en las áreas más remotas de América y Siberia. En consecuencia, cualquier enfoque ecológico que considere estas acciones humanas, ubicuas y milenarias, como "desviaciones", es poco realista. La historia socioeconómica está en la base de los atributos ecosistémicos que hoy día se pueden observar, y no sólo en las estructura sino también en las dinámicas.

La influencia de la economía en la configuración de los ecosistemas se hace muy evidente en grandes extensiones, hasta el punto que es fácil averiguar el grado de desarrollo económico de un país estudiando sus montes (ver una revisión de etapas socioeconómicas en los montes en SeviLla, 2008). Pero en realidad la economía condiciona, y lo ha hecho en el pasado, la estructura y dinámica forestal a todas las escalas, incluyendo las de mayor detalle (por ejemplo, en la arquitectura de los árboles trasmochos todavía se perciben los efectos de los aprovechamientos tradicionales, incluso en bosques no explotados durante un siglo). Por eso, cuando en el estudio de los ecosistemas se prescinde de los aspectos económicos, y de los sociales asociados, se está renunciando a una parte crucial de la interpretación de la realidad.

Se debe avanzar hacia una convergencia de ecología y economía, que no deben ser concebidas una al margen de la otra. La disociación de economía y ecología acaba por repercutir negativamente en ambas: el conservacionismo que no tiene en cuenta a los seres humanos (ni como factor clave en los procesos que configuran los ecosistemas ni como sujetos finales a cuya satisfacción se dirige la conservación) y el economicismo cortoplacista son dos extremos que en realidad son dos caras de la misma moneda, que no es otra que la de la ausencia de integración entre economía y ecología.

La ecología global, planetaria, nos indica que debemos ser mucho más comedidos en el uso de los recursos, en especial de los no renovables, y mucho más eficientes en los procesos. Economía y ecología se funden en los flujos globales. El consumismo irreflexivo y la falta de perspectiva a largo plazo llevan al colapso ecológico y económico, tanto de países y civilizaciones como en un futuro del planeta si no se reacciona a tiempo (ver DiAMOND, 2005). La 
madera, además de renovable, exige menos procesado y menos consumo de energía que otros materiales alternativos. Países como España no pueden permitirse infrautilizar sus recursos por absurdos prejuicios, y no sólo por evidentes motivos económicos, sino ecológicos a varios niveles: para gestionar los montes y lograr las estructuras forestales deseadas, y para limitar el consumo de materiales más contaminantes o la explotación forestal en países con menos posibilidades de que se efectúe de forma ordenada. Los forestales, como probablemente ningún otro sector, han aprendido a manejar los recursos de forma sostenible, lo que es muy encomiable en unos ecosistemas en los que las acciones tienen efectos de tan largo alcance. El hecho de que hayan sido pioneros en la sostenibilidad ha sido causado porque la falta de madera y, en menor medida, de otros productos forestales, debido a su importancia y excesiva explotación, llevó ya hace muchos siglos a promulgar disposiciones que garantizasen un uso racional del recurso: ha sido muy difícil en la historia de la humanidad anticipar los grandes problemas ecológicos.

Tradicionalmente economía y ecología se han visto como disciplinas con escasos puntos de conexión y opuestas en sus objetivos. En montes o rodales incluso es frecuente hablar de destino a producción o a protección, como si ambos objetivos fuesen antagónicos y hubiese siempre que escoger uno preferente, cuando más bien lo que habría que asumir es que sin producción no puede haber gestión (salvo acciones puntuales), ni por tanto se pueden lograr objetivos de conservación más allá de los que resulten de la no actuación, en muchos casos inopinadamente. Quizá esa dicotomía es producto de una visión muy superficial, motivada por un desconocimiento del ecosistema y sus potencialidades, y estimulada por la visión maniquea que predomina en la sociedad. A diferencia de otros sectores, en el forestal lo más favorable en términos económicos frecuentemente produce unos resultados ecológicos muy aceptables. Otra cosa es que no se echen bien las cuentas o que éstas se hagan sólo a corto plazo. Pero, en general y a largo plazo no son muy rentables sistemas de gestión forestal que necesiten constantemente aportes del hombre en forma de actuaciones drásticas, utilización masiva de productos fitosanitarios o abonos. Algunos de los sistemas más artificiales han tenido un notable éxito económico porque nunca se han evaluado correctamente sus riesgos y además éstos han sido cubiertos por la Administración y no repercutidos a los propietarios, por ejemplo mediante sistemas de prevención y extinción de incendios forestales, de plagas, subvención a las repoblaciones, etc.

Mucho se ha debatido acerca de buenos indicadores de la gestión forestal. Con frecuencia se postula la biodiversidad, pero plantea problemas porque no recoge la parte socioeconómica de la gestión y porque se obtienen resultados discordantes en función del enfoque adoptado, de la escala utilizada, los grupos de seres vivos incluidos, etc. El dinero obtenido a largo plazo podría emplearse como indicador de la bondad de la gestión en un ecosistema; tanto para evaluar la gestión pasada como guía para futuras decisiones. El dinero tiene la ventaja de que existe una amplia y contrastada experiencia en asignar valor monetario a todo tipo de bienes y servicios. Por supuesto no está exento de problemas, como cualquier indicador, pero sirve al objetivo de sintetizar información que de otra forma es muy difícil encajar en un sistema único de valoración: posibilita la comparación de alternativas dispares. Exige otorgar valor a procesos ecológicos, al paisaje, a la diversidad, pero en realidad eso se hace continuamente por ejemplo en los estudios de impacto ambiental (otra cosa es que ese valor no se monetarice). Debería establecerse un valor muy elevado a bienes cuyo coste de reposición también lo sea o si es muy largo el tiempo para la reversión al estado previo en caso de degradación. En este sentido, al menos el capital suelo y el acervo genético deben computarse como bienes de valor económico muy alto, independientemente de que su valor de mercado pueda ser bajo o inexistente: no son sujetos habituales de tráfico mercantil pero constituyen parte esencial de las capacidades productivas del ecosistema y de su funcionamiento ecológico.

Está extendida la idea, incluso entre los forestales, de que económicamente lo mejor que se puede hacer con un bosque es cortarlo a hecho y meter el dinero en un banco o realizar una inversión en inmuebles. La actual crisis ha puesto de relieve algo que a mi modo de ver ya ocurría antes, y es que los bosques, con un manejo adecuado, son 
una buena inversión. De hecho, en muchos lugares del mundo, bosques con aptitud maderera son comprados por fondos de inversión, de pensiones o por particulares que buscan rentabilizar su inversión con un aprovechamiento sostenible y a través de la capitalización del monte, que casi siempre aumenta de valor si la gestión es adecuada.

\section{LA PREDICCIÓN ECOLÓGICA}

La prognosis o conocimiento anticipado de los sucesos debería ser la vara de medir la bondad de la ciencia ecológica. Por supuesto que la explicación de los hechos pasados es decisiva, pero con énfasis en la medida en que el pasado nos sirva para predecir el futuro: es la aplicación del principio de actualismo, que hay que adoptar con precaución en ecología, por los constantes cambios en los procesos (aunque no en algunos principios, que parecen más inmutables).

El conocimiento anticipado de todos los detalles no es posible, pero sí unas líneas generales más probables de organización del ecosistema. Conocidas éstas, es fácil colegir las repercusiones sobre especies en concreto. $\mathrm{La}$ opción inversa, esto es, estudiar y gestionar especies con la esperanza de que las acciones sobre ellas sean decisivas para el conjunto, es un ejercicio de optimismo.

El nexo de unión entre ciencia y técnica debería estribar en una capacidad de predicción compartida, por mucho que la investigación y la gestión usen tácticas diferentes y hasta un lenguaje propio. Sin predicciones acertadas la ciencia se vuelve fútil y la aplicación práctica temeraria. La necesidad de intervenir en los montes es tan básica como recordar el origen de los recursos que usa la humanidad, y que España no puede renunciar a la mitad de su territorio. Los constructos intelectuales no predictivos son divertimentos científicos (no-teorías).

Una buena representación de la situación previa y la comprensión del funcionamiento ecológico en una zona concreta son las bases para efectuar la predicción. Dentro de los componentes del ecosistema la atención se centra aquí en la vegetación dominante, por su papel clave en la dinámica general, y porque su menor movilidad (respecto a los animales) y su mayor visibilidad (respecto a hon- gos y seres diminutos) la convierten en más fácil de modelizar. De particular importancia es el conocimiento de los atributos vitales de las especies implicadas, y en concreto de:

Tolerancia a la concurrencia

Velocidad de crecimiento en altura en cada periodo de desarrollo

Talla máxima

Longevidad

Capacidad de reproducción vegetativa

Mecanismos de dispersión

Resistencia frente al fuego

Apetencia y resistencia frente a fitófagos

Sensibilidad frente a plagas y enfermedades

Estos atributos se deben evaluar a varias escalas y desde varios enfoques: atributos característicos de la especie, su manifestación en la comarca y en el rodal concreto, y su concreción en cada individuo.

Los ecosistemas forestales, por muy simplificados que estén o por muy homogéneos que se muestren en apariencia, son siempre sistemas complejos: intervienen multitud de organismos, de distintas especies y edades, en un medio heterogéneo, con una intrincada historia previa y un amplio abanico de combinaciones y dinámicas posibles. Aunque en los ecosistemas todo está determinado por las condiciones de partida (posicionamiento filosófico determinista), su inabordable complejidad y unas reglas de funcionamiento que siempre serán imperfectamente conocidas, impiden que la precisión de las predicciones abarque todos los detalles. Además, en los ecosistemas, la herencia afecta a largo plazo, con efectos diferidos que no son fáciles de prever.

Es una tarea en exceso ardua parametrizar en gabinete todos los factores que influyen en la dinámica de los ecosistemas, y todavía más si se pretende integrar su efecto conjunto. Sin embargo los árboles y otras plantas, al tener un crecimiento modular y en cada periodo estar afectados por esos factores, constituyen un magnífico registro, que compendia el origen de las distintas generaciones presentes (OLDEMAN, 1990), el medio geoclimático, las variaciones interanuales, daños de diverso tipo (fuego, climáticos, fauna, enfermedades, mecánicos), etc. Para interpretarlo es muy útil conocer cuáles son los patrones de desarrollo prefijados genéticamente, así como las velocidades de creci- 


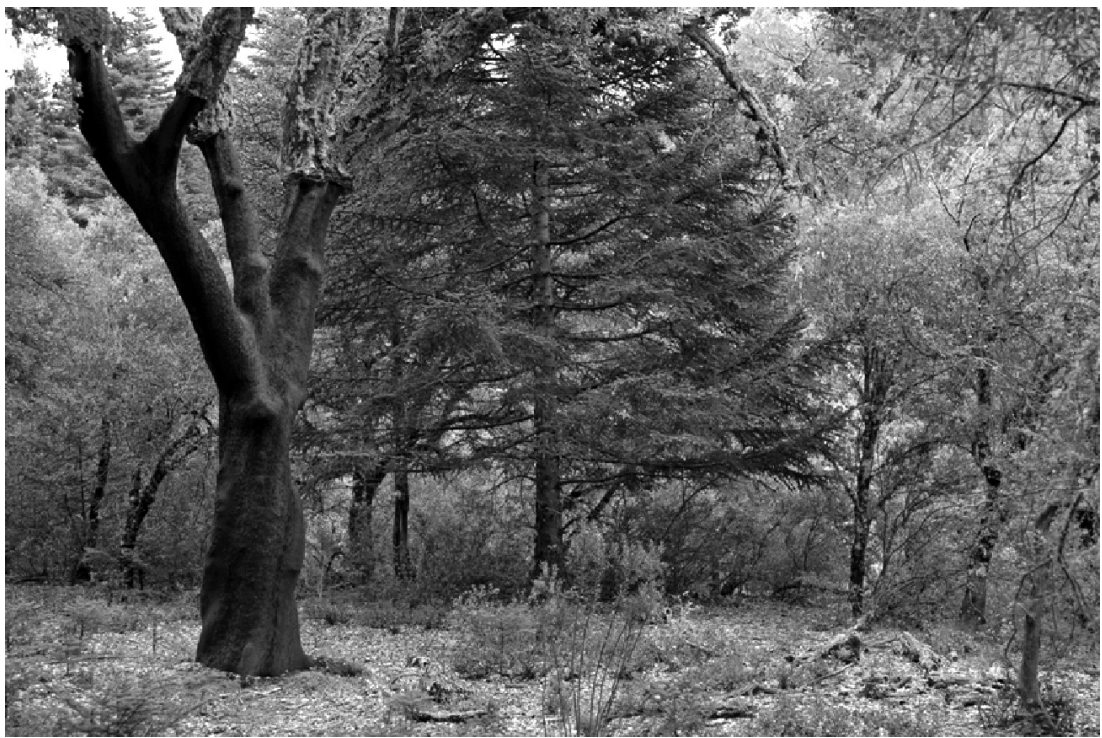

Figura 2. La concurrencia en un espacio vegetativo que es limitado es un factor físico de primer orden que explica en parte las dinámicas a escalas de bosquete y rodal. Lo que ocurre bajo el suelo está menos estudiado pero lo que se puede observar sobre él parece resultar determinante. Aquí se aprecia cómo un pinsapo expande su copa donde ni las jóvenes encinas ni el gran alcornoque lo pueden hacer, gracias a la elevada tolerancia que caracteriza a todas las especies del género Abies. Encinas y alcornoques son entre sí próximos en tolerancia, pero la encina parece ser ligeramente más tolerante, lo que la favorece en la tendencia sucesional. Se observa abundante regeneración anticipada de pinsapo (Parauta, Málaga)

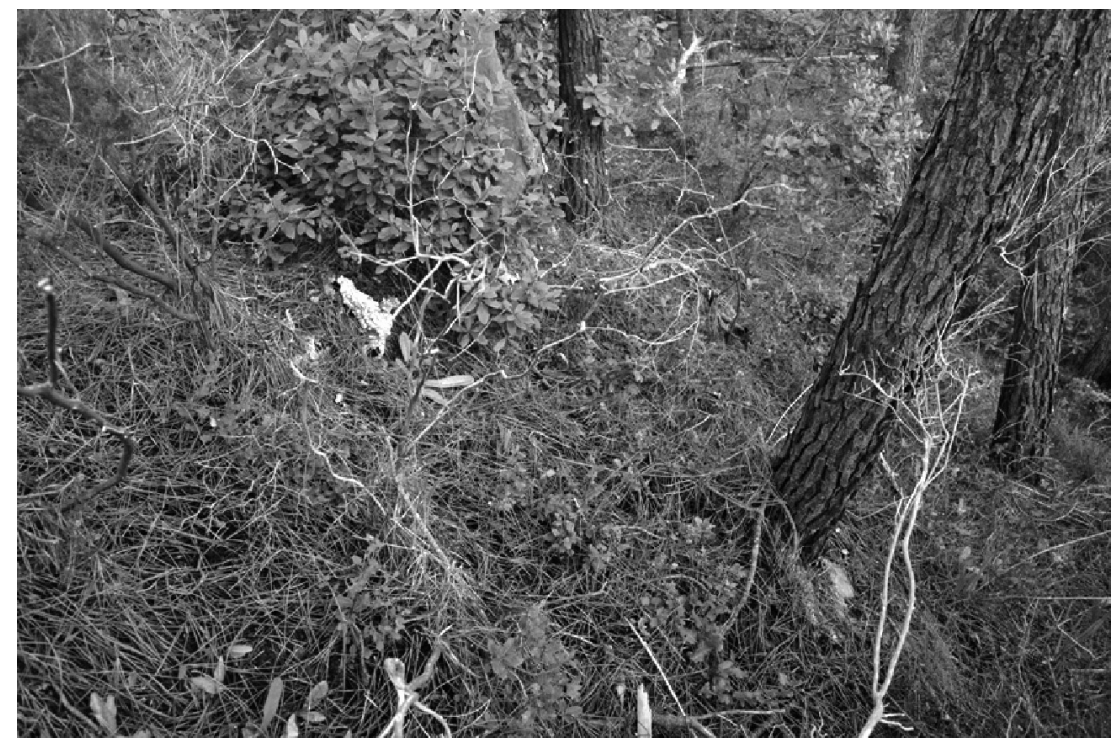

Figura 3. Sucesión vegetal bajo un rodal de Pinus pinaster: mientras que las matas y arbustos heliófilos (en concreto aquí jaras -Cistus ladanifer- y brezos -Erica arborea-) van sucumbiendo, el madroño y en menor medida el alcornoque van ocupando el espacio vegetativo que va quedando disponible. Es la fase de reposición (Carrapateira, Portugal) 


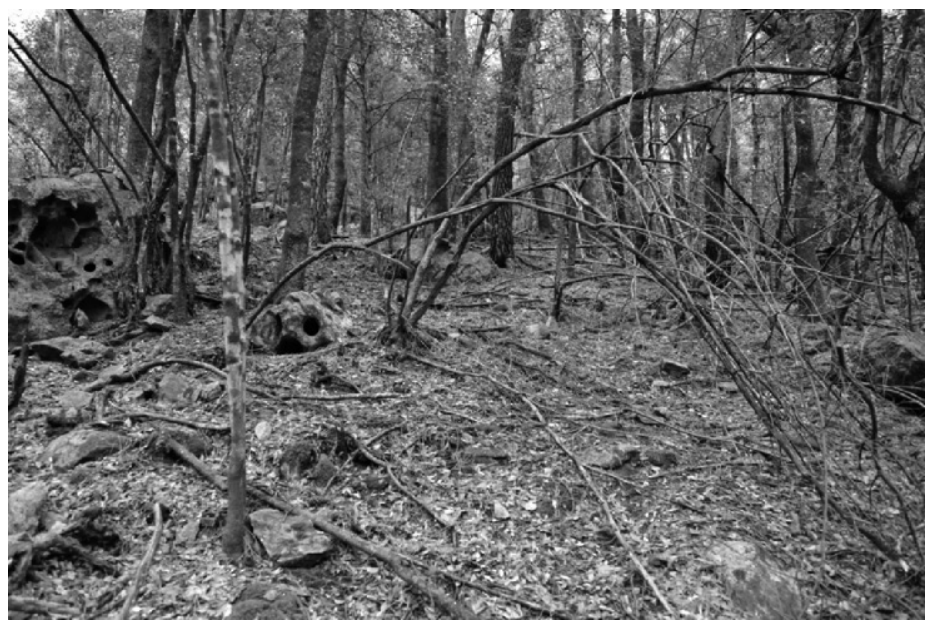

Figura 4. Imagen que guarda algunas semejanzas con la anterior, pero en la que el arbusto que sucumbe por la excesiva concurrencia es el madroño (Arbutus unedo): bajo el rodal con grandes Pinus pinaster y una generación más joven de encinas (Quercus ilex), se ven gran cantidad de madroños muertos, mientras que los acebos (Ilex aquifolium) resisten bien la concurrencia y mantienen la verticalidad (destaca uno en primer término, a la izquierda). La tolerancia es un atributo holístico, ecosistémico, es decir, más que inherente a especies o individuos adquiere su verdadera significación en cada contexto ecológico concreto (Bosque de Bonifatu, Córcega, Francia)

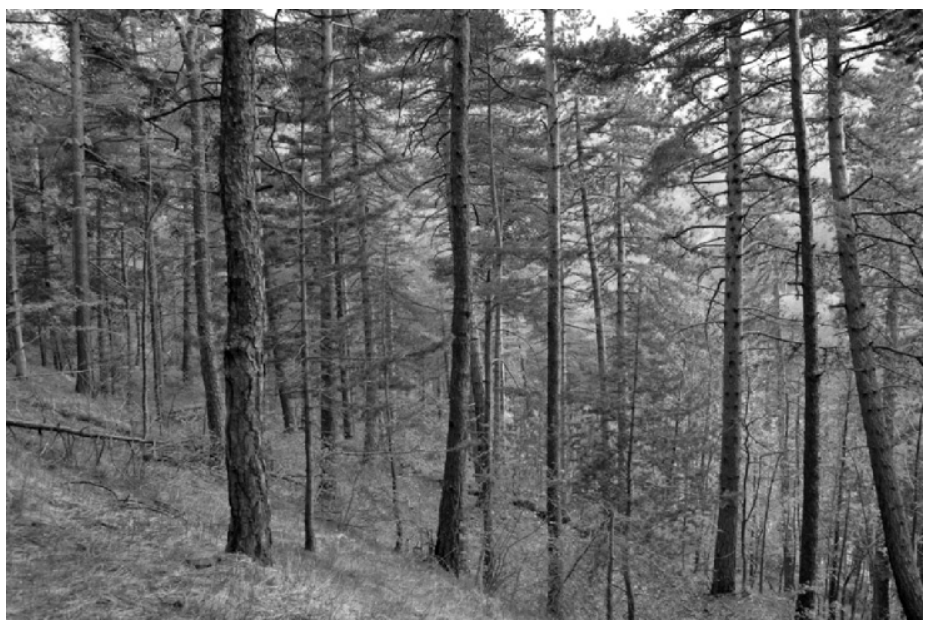

Figura 5. Un principio bastante general es que los individuos de una especie tienen muchas dificultades para desarrollarse bajo dosel denso de su propia especie u otras especies semejantes. Es tan general ese patrón que podría pensarse que es un principio de imposibilidad, de los escasos que contribuyen a acotar las predicciones y que no abundan mucho en ecología forestal. Pero incluso en este caso es posible encontrar excepciones, como en este rodal dominado por grandes ejemplares de Pinus sylvestris y Pinus nigra, en el que se aprecia cómo algunos pies de pino silvestre han logrado sobrevivir y crecer bajo la espesa cubierta (la sombra arrojada por Pinus nigra no es menor ni más estacional que la de P. sylvestris). Es preciso tener en cuenta la variedad intraespecífica en la dinámica forestal. En realidad esto supone más un problema teórico que práctico: si se encuentran individuos tolerantes de especies intolerantes, se puede esperar de ellos el comportamiento que corresponde a un mayor grado de tolerancia, sin importar su adscripción taxonómica (lo mismo sirve para otros atributos vitales). Además de los pinos se ve regeneración anticipada de Sorbus aucuparia, Prunus avium, Acer pseudoplatanus y Fraxinus excelsior, especies todas ellas clasificadas como más tolerantes que los pinos y que por tanto no es sorprende encontrar en el subpiso (Fenestrelle, Italia) 


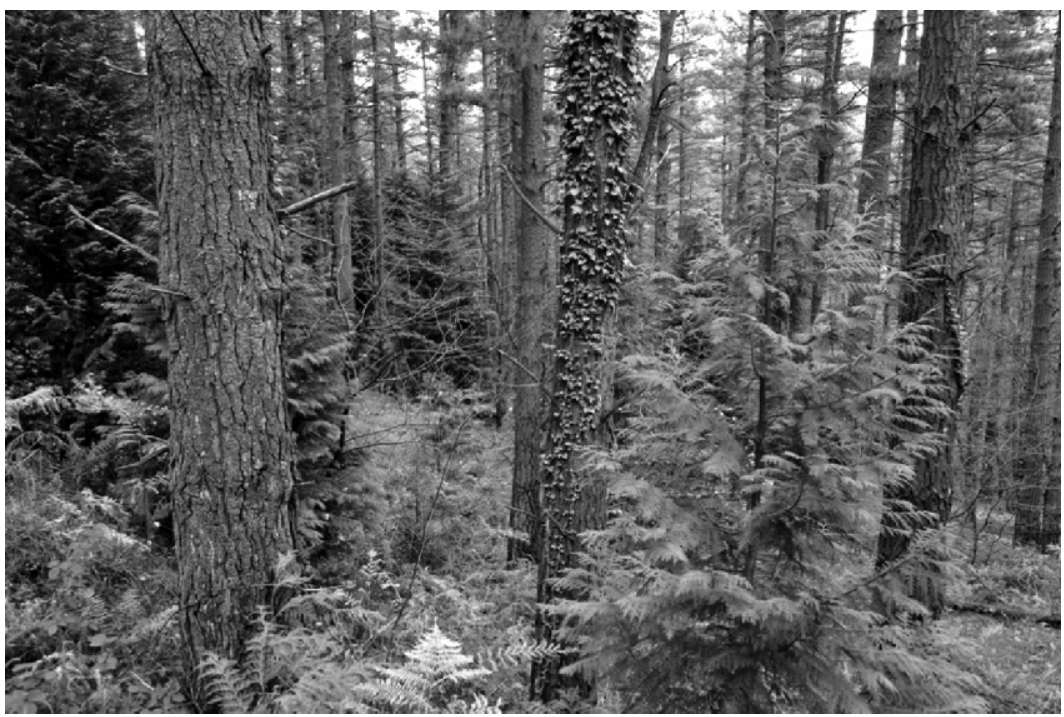

Figura 6. Abundante regeneración anticipada de Chamaecyparis lawsoniana bajo repoblación de Pinus radiata. En la dinámica espontánea de este rodal se integran frondosas nativas como haya, roble, castaño, encina, mostajo, avellano y acebo, que forman también regeneración anticipada bajo los pinos. La predicción del comportamiento sucesional es indiferente al hecho de que las especies que intervengan sean exóticas o no. En Norteamérica Chamaecyparis es mucho más tolerante que Pinus y en la Península Ibérica el comportamiento es el mismo. De forma complementaria resulta ilustrativo analizar el comportamiento de especies nativas de España fuera del ámbito ibérico (Valle de Carranza, Vizcaya)

miento características de la calidad de estación en la que se ubique el rodal o bosquete. Conocida la arquitectura de las especies y comparándola con la que se observa en el campo, se puede obtener mucha información acerca de los factores más decisivos en el desarrollo del bosquete (ver un amplio repertorio de ejemplos en SEVILLA, 2008).

Hoy día existen suficientes conocimientos para predecir la evolución de un ecosistema forestal con precisión adecuada para muchos objetivos. Los modelos predictivos deben ser:

- Espacialmente explícitos

- Dependientes de la escala

- Deben utilizar los atributos vitales de las especies implicadas

- Deben integrar el efecto de la fauna, tanto doméstica como silvestre, y del hombre

- Deben integrar el efecto de los eventos renovadores (a múltiples escalas)

\begin{tabular}{|l|l|}
\hline Tipo de proceso & Tipo de predicción \\
\hline Regeneración & Probabilística/mecanicista \\
\hline Crecimiento libre & Mecanicista \\
\hline Desarrollo en concurrencia & Mecanicista \\
\hline Superación a otras plantas & Mecanicista \\
\hline Susceptibilidad a renovarse & Mecanicista \\
\hline Daños por fitófagos & Mecanicista \\
\hline Daños climáticos & Probabilística \\
\hline Daños por plagas y enfermedades & Probabilística \\
\hline Mortalidad planificada & Mecanicista \\
\hline Mortalidad espontánea & Probabilística \\
\hline
\end{tabular}




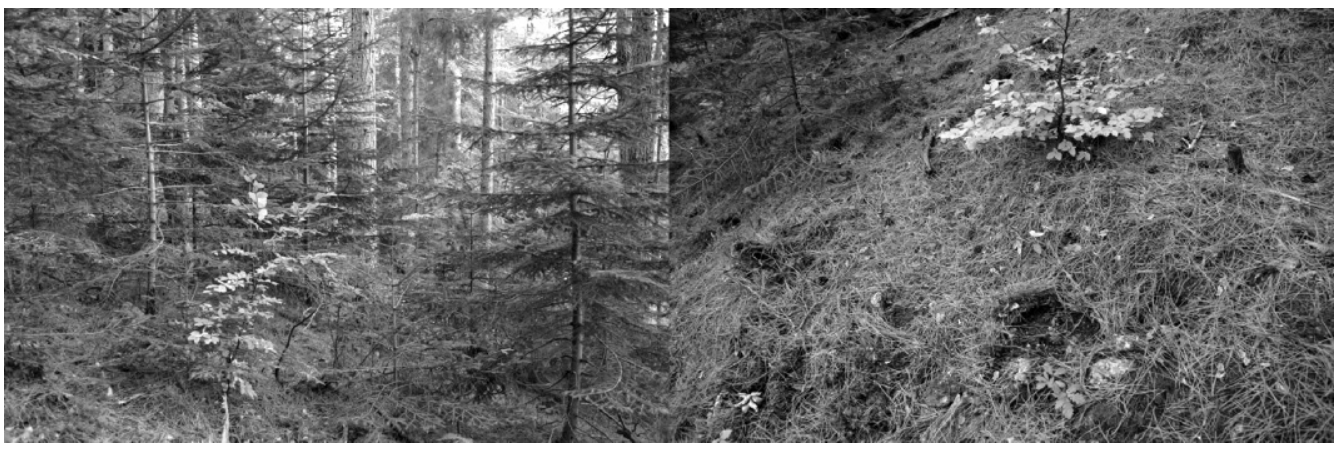

Figura 7. Pinar de P. nigra con abundante regeneración anticipada de abeto (Abies alba) y haya (Fagus sylvatica), que se desarrolla con vigor. Muchos otros árboles se regeneran bajo el pinar en este rodal, gracias a que disponen de fuente de semilla: pinos, robles, castaños, encinas y abedules (en la imagen de detalle se aprecian un roble y un castaño); pero no son lo suficientemente tolerantes y no son capaces de conseguir relevancia en el subpiso. En este caso han funcionado las reglas generales y la sucesión va siguiendo la ruta prevista, algo que en el ejemplo de la figura 5 ocurría en menor medida. Los procesos de regeneración se pueden modelizar en función de las fuentes de semilla, pero están sometidos a muchos factores de los que se tiene sólo un conocimiento parcial, como el comportamiento de los animales dispersores o los vientos concretos que resultan más decisivos; por eso se dice que son procesos estocásticos en un elevado grado. Sin embargo, el desarrollo bajo distintas condiciones de iluminación, y la arquitectura resultante de los pies sí es susceptible de una predicción mecanicista (aunque siempre habrá factores imprevistos como daños por eventos climáticos o por fauna) (Col de Verde, Córcega, Francia)

En los ecosistemas, los límites entre tipos de predicción son difusos. El mecanicismo en los montes siempre tiene un margen de incertidumbre mayor que en sistemas más simples (como las máquinas que construyen los hombres). De forma complementaria, los procesos para los que se ha prescrito predicción probabilística no son completamente estocásticos, pues dependen de condiciones iniciales modelizables y además existe un elevado grado de conocimiento del proceso en sí. En concreto la regeneración es intermedia porque depende en gran medida de las fuentes de semilla y de las capacidades de dispersión de las especies, pero lo cierto es que a pesar de que los forestales durante siglos la han estudiado todavía existen considerables incertidumbres, sobre todo para las especies dispersadas por animales. Entre los procesos trascendentales para comprender la dinámica vegetal, el menos previsible es el del fin de los individuos dominantes, excepto lógicamente cuando éste se planifica y ejecuta (normalmente mediante cortas, pero también quemas controladas, desbroces, y otras formas). Aunque las predicciones climáticas han mejorado mucho, todavía la predicción a medio y largo plazo es más probabilística que mecanicista, si bien los modelos cada vez incluyen más precisión en las condiciones iniciales y un mejor conocimiento de los procesos. La consecuencia es que los eventos en los que interviene de forma decisiva el clima (incendios, derribos, aludes, sequías, granizadas, heladas, deslizamientos de ladera, inundaciones, muchas plagas y enfermedades) no se pueden considerar hoy en día susceptibles de predicción mecanicista. Tampoco lo es la muerte de árboles individuales por causas pocas veces completamente esclarecidas, normalmente atribuida a plagas, enfermedades, sequías y otros eventos climáticos, o simplemente a decaimiento asociado a la edad y al gran tamaño. La mortalidad por excesiva concurrencia, bien conocida en sus líneas generales pero no en el momento preciso en que ocurre, caería en una categoría intermedia.

\section{INCERTIDUMBRE Y "ANTIFRAGILIDAD"}

La vida en la Tierra ha evolucionado superando vicisitudes de todo tipo, algunas de pequeño alcance y otras que han revolucionado por completo las condiciones en las que se desenvolvían los organismos y las relaciones entre ellos. En el código genético de los seres vivos ha quedado impresa la huella de eventos renovadores variados que quizá solo tengan en común que los extremadamente intensos (como los que llevaron 
a la extinción de los dinosaurios) son mucho menos frecuentes que los de menor afección y extensión (MARGALEF, 1991). Este atributo de todos los sistemas vivos choca con el deseo de los seres humanos de vivir en un mundo predecible, así como con cualquier planteamiento o teoría ecológica que no tenga en cuenta esta propiedad esencial de los ecosistemas.

Debemos dejar de percibir las inevitables incertidumbres en las predicciones ecológicas como algo negativo y que paraliza las decisiones de gestión: la incertidumbre es consustancial a los sistemas complejos y debemos diseñar nuestros montes de forma que sean poco vulnerables frente a lo inesperado, incluso para que se beneficien de ello, para que sean "antifrágiles" (TALEB, 2012). En este sentido, y con un carácter general, las recomendaciones de gestión frente al cambio climático son las mismas que frente a los riesgos en general, incluidos los económicos. Interesa tener ecosistemas heterogéneos a todas las escalas, diversos en cuanto a su composición específica, con variedad de estructuras y de clases de edad aunque no en exceso envejecidos, dominados por individuos vigorosos, con capacidad de adaptación y de soportar distintas formas de estrés.

\begin{tabular}{|ll|}
\hline Fragilidad & Robustez, antifragilidad \\
\hline Homogeneidad & Heterogeneidad \\
\hline Simplificación específica & Diversidad genética \\
\hline Decadencia & Vigor \\
\hline Coetaneidad & Amplio abanico de generaciones \\
\hline Ausencia prolongada de renovaciones & Eventos moderados y frecuentes \\
\hline Ecosistemas no testados por la evolución & Especies nativas \\
\hline El modelo teórico es lo que importa & $\begin{array}{l}\text { Lo importante son los procesos que efectivamente } \\
\text { tienen lugar }\end{array}$ \\
\hline Ausencia de referencias de escala & Enfoque multiescalar \\
\hline Insuficiente concreción espacial & Modelos espacialmente explícitos \\
\hline Uso exclusivo de métodos cartesianos & $\begin{array}{l}\text { Apertura a todo tipo de herramientas de estudio, } \\
\text { incluidas algunas heterodoxas }\end{array}$ \\
\hline Reduccionismo & Holismo \\
\hline Ignorancia de la historia & Precedentes bien documentados \\
\hline Planteamientos estáticos & Gestión basada en procesos \\
\hline Orientación a un único objetivo & Gestión multiobjetivo \\
\hline Ausencia de procesos de definición de objetivos & Objetivos claros y cuantificables \\
\hline Cortoplacismo & Balance entre objetivos a corto y largo plazo \\
\hline Recetas, prescripciones genéricas & $\begin{array}{l}\text { Las decisiones se toman en función de los precisos } \\
\text { atributos del rodal y de su contexto }\end{array}$ \\
\hline Ordenación territorial inadecuada o inexistente & Gestión forestal inserta en ordenación del territorio \\
\hline Planificación prolija e inoperante & Estrecha vinculación entre gabinete y campo \\
\hline Multitud de jefes & Organización jerárquica \\
\hline Deficiente asignación de funciones & Competencias bien delimitadas \\
\hline Incomprensión. Decisiones impuestas & Amplia base social \\
\hline Descoordinación & Objetivos compartidos \\
\hline Responsabilidad difusa & Cada actor responde por sus errores \\
\hline Productos de poco valor & Productos de calidad \\
\hline $\begin{array}{l}\text { Viales que se construyen para fines } \\
\text { coyunturales, sin visión de conjunto }\end{array}$ & $\begin{array}{l}\text { Red viaria que permite una gestión territorial acorde } \\
\text { con los objetivos }\end{array}$ \\
\hline Uso masivo de fertilizantes, fitosanitarios & Utilización de las dinámicas espontáneas \\
y otros productos químicos & \\
\hline & \\
\hline
\end{tabular}




\begin{tabular}{|ll|}
\hline Intervenciones costosas & Acciones puntuales \\
\hline Inseguridad jurídica & Normas precisas y asumidas por todos \\
\hline Gestión basada en “no-teorías" & Conocimiento profundo \\
\hline La incertidumbre es percibida como amenaza & $\begin{array}{l}\text { Se asume que los montes son sistemas complejos y la } \\
\text { incertidumbre como inherente }\end{array}$ \\
\hline Ecología académica & Conocimiento empírico \\
\hline Autocomplacencia & Revisión crítica continua \\
\hline Ocultación de las carencias & Identificación y exhibición de los errores \\
\hline Inmovilismo & Innovación continua \\
\hline Deslumbramiento por lo nuevo & Utilización de métodos testados \\
\hline Prejuicios & Análisis de resultados \\
\hline Se asume la continuidad de los factores & Preparación para “escenarios sorpresa" \\
\hline Dependencia de fondos públicos & Rentabilidad \\
\hline Deuda & Reinversión \\
\hline Mecanismos erráticos de toma de decisiones & Gestión adaptativa \\
\hline Burocracia & Decisiones en el monte \\
\hline Monopolios & Mercado transparente y bien desarrollado \\
\hline Planificación rígida & Flexibilidad, oportunismo \\
\hline Ecología opuesta a economía & Contabilidad holística \\
\hline $\begin{array}{l}\text { Gestión/no-gestión desvinculada del contexto } \\
\text { socioeconómico }\end{array}$ & Cadena monte-industria bien desarrollada e integrada \\
\hline Endogamia, autarquía & Apertura al exterior \\
\hline Gestión a la defensiva & Gestión anticipadora \\
\hline Aprovechamientos tras eventos destructivos & Estructuras producto de un diseño previo \\
\hline Intervenciones drásticas & Aprovechamientos frecuentes y planificados \\
\hline
\end{tabular}

Tabla 1. Atributos asignables a los conceptos de fragilidad y robustez en ecosistemas

La Tabla 1 expuesta encierra ciertas contradicciones e indefiniciones que en la aplicación práctica es necesario resolver. Así el oportunismo (antifrágil) se puede entender como muy semejante al cortoplacismo (frágil): la diferencia estriba en que el oportunista debe actuar conociendo los comportamientos a largo plazo pero aprovechar el momento; esto no siempre (casi nunca) es fácil, y entre otros baremos servirá para calificar la calidad de la gestión (a la luz de los resultados).

Estas ideas generales acerca de la fragilidad y la robustez deben luego concretarse en cada contexto. Un ecosistema es más o menos frágil frente a un tipo de evento, pero no sólo importa el tipo sino sus magnitudes (afección, extensión, frecuencia). Además el asunto dista mucho de ser simple. Por ejemplo, respecto al fuego, no está claro si son preferibles ecosistemas muy resilientes (que retornan a la situación previa al incendio con rapidez) $\mathrm{u}$ otros que lo sean menos pero que generen estructuras menos combustibles: especies como Pinus halepensis o Quercus pyrenaica cuentan con formidables mecanismos para reconstruir sus bosques tras un incendio (por semilla y brote, respectivamente), pero generan estructuras que con carácter general son más susceptibles a quemarse intensamente que otros árboles como Pinus nigra o Fagus sylvati$c a$, especies mucho menos resilientes frente al fuego pero que, gracias a que arrojan una sombra más densa, posibilitan una rápida expulsión del matorral heliófilo, principal propagador de las llamas. También se trata de una cuestión temporal: antes de culminarse la fase de expulsión las diferencias de combustibilidad son irrelevantes. En cada lugar y momento concretos, la precisa distribución de ecosistemas y los objetivos de gestión constituyen el marco que debe 
servir para tomar las decisiones oportunas. Es importante no estar sesgados por apriorismos de ningún tipo, incluida la preferencia por los ecosistemas resilientes, entre otros motivos porque el sistema agrario tradicional ha constituido una importante fuerza selectiva durante milenios a favor de la resiliencia más extrema, lo que explica por ejemplo la profusión de especies rebrotadoras, o la extensión superficial de formaciones monoespecíficas dominadas por Quercus ilex o Q. pyrenaica (ver Figura 1): con el fin de la presión excesiva sobre los montes se pueden promover ecosistemas más diversos y adecuados a los servicios que de ellos se espera.

Se debe avanzar en la predicción de los eventos renovadores: si se asume que son una parte esencial en la configuración de los ecosistemas no podrá existir prognosis adecuada que no los tenga en cuenta. El análisis de las renovaciones pasadas y sus efectos ecológicos es un trabajo sumamente útil para mejorar el conocimiento de los comportamientos dinámicos y en concreto la predecir la repercusión de las acciones u omisiones. En este sentido, la distinción entre eventos naturales y humanos es irrelevante: los efectos no dependen del origen, sino de la precisa ubicación y de magnitudes como grado de afección, extensión y frecuencia (SEVILLA, 2008).

A pesar de la evidente influencia de los eventos renovadores, el estudio de los acaecidos en el pasado y de su efecto no ha sido prioritario, probablemente por el desafío que supone retrotraerse siglos o milenios, y por la dificultad de reducir a parámetros numéricos la influencia de una historia de eventos nunca bien conocida. No obstante, los obstáculos para su integración en los modelos no deberían llevar a obviar una parte fundamental de la explicación de la realidad: los eventos renovadores no son algo ajeno al ecosistema, sino parte consustancial a él y decisivo en su configuración. Tampoco son algo totalmente impredecible. Son el punto en el que se une la predisposición del ecosistema a renovarse y la acción de agentes (fuego, viento, nieve, fitófa-

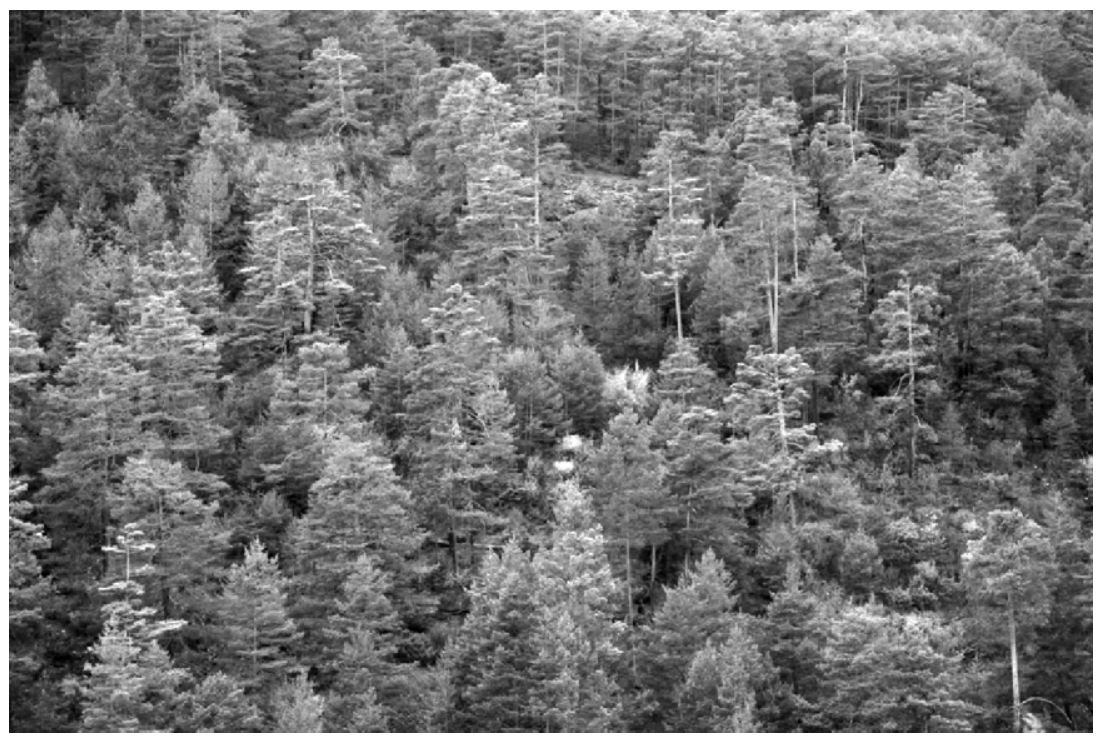

Figura 8. Los bosques se van a renovar, de forma planificada o siguiendo pautas espontáneas. Si no se realizan claras y cortas de regeneración los árboles inevitablemente se acabarán derribando, secando o quemando: como todos los seres vivos, están abocados a la muerte. Si ésta no llega a través de una renovación total del rodal, opera a nivel individual. En las plántulas las causas más habituales son el exceso de concurrencia y la herbivoría. En los árboles viejos existe un amplio elenco que incluye plagas, enfermedades, sequías, problemas acumulados, fallos sistémicos, etc. En la imagen se aprecia cómo los pinos silvestres jóvenes se muestran vigorosos mientras que los de mayor tamaño se encuentran coronados, cloróticos, con abundante muérdago y algunos han sucumbido. La coexistencia de varias generaciones previene el riesgo de muerte masiva (Tramacastilla, Teruel) 
gos, taladores, roturadores, etc.) que no son completamente predecibles pero tampoco totalmente impredecibles, es decir, que se pueden encajar en una categoría sumamente común en ecología.

En la predicción de eventos renovadores siempre va a existir una importante dosis de indeterminación. Por ejemplo, podríamos teóricamente averiguar la serie de incendios forestales que han acaecido en una determinada comarca; para los incendios ligeros analizando las décadas recientes y para los de más intensidad extendiendo el periodo de estudio a siglos o incluso milenios (para lo que habría que usar técnicas de paleoecología). Podríamos incluso, con mucho esfuerzo y no pocos costes y dificultades, lograr ubicar espacialmente las superficies quemadas. De esta forma obtendríamos el patrón de incendios común, los lugares de ocurrencia más probables, una distribución estadística del tipo de incendios a lo largo de los meses, años o décadas, etc. Analizando las estructuras actuales del monte y sus dinámicas podríamos tener una estimación razonable de la combustibilidad del monte y de cómo podría afectar el fuego si se inicia en según qué condiciones. Pero sería imposible predecir con precisión cuándo y dónde sucederá el próximo incendio, y sus consecuencias. Esto mismo se podría aplicar a los derribos, plagas y cualquier otro evento renovador no planificado e implementado por el hombre. Asumiendo la incertidumbre inherente el objetivo es ir delimitándola. Por ejemplo, no todos los montes arden con la misma facilidad o virulencia, ni en todos los momentos igual. Incluso hay situaciones en las que el monte no arde, bien por condiciones meteorológicas (lo más frecuente) o por características estructurales (por ejemplo, un rodal de hayedo sin sotobosque ni hojarasca). Es decir, es posible delimitar trayectorias ecológicas que no podrán existir, y otras que muy difícilmente. Entre las opciones posibles, no todas serán igual de probables.

\section{LA TRANSFORMACIÓN SOCIOECONÓMICA Y ECOLÓGICA DE ESPAÑA REQUIERE UN CAMBIO DE PARADIGMAS}

En los años 60 del siglo XX se produjo en España el cambio socioeconómico de mayor trascendencia de los últimos siglos, en un proce- so bien conocido que podemos denominar como el fin del sistema agrario tradicional. Éste había causado la explotación por encima de los umbrales de sostenibilidad, la casi desaparición de los bosques en las llanuras, erosión generalizada en los sistemas montañosos, falta de regeneración, etc. Situación a la que los forestales de la época intentaban poner freno en la medida de sus posibilidades y luchando contracorriente en un medio rural falto de recursos para suplir la abundante población que de él dependía. Con la emigración a las ciudades y la menor dependencia del monte, éste se vio por fin libre de la tremenda presión que había soportado de manera creciente durante milenios, lógicamente con vaivenes. Los efectos de este brusco descenso de la presión de explotación son también bien conocidos: aumento de existencias, acumulación de combustibles, incendios que adquieren una virulencia y dimensiones novedosas, y en resumen cambio generalizado de dinámicas y estructuras forestales. Es llamativo cómo los bosques, una vez superado cierto umbral de recuperación, crecen aceleradamente, de forma que supera las expectativas, según muestran los inventarios de montes y los que se realizan en el conjunto de España (ver los datos del Inventario Forestal Nacional; ya están disponibles los del Cuarto para varias comunidades autónomas).

Tras aproximadamente medio siglo de recuperación forestal, los montes han pasado de la sobreexplotación al abandono, y sin embargo las concepciones y paradigmas sobre ellos apenas han cambiado, ni entre los profesionales que siguen considerando la ausencia de intervención por incapacidad (no por decisión) como una forma de conservación (para algunos incluso la mejor), ni entre la sociedad en general que sigue creyendo que los bosques siguen disminuyendo. Da la impresión que los montes, a pesar de su aparente quietud, cambian más rápido que las estructuras mentales respecto a ellos. Es urgente una profunda revisión de los paradigmas forestales dominantes que tenga en cuenta el nuevo contexto. Entre otras cuestiones, es necesaria una reorientación profunda del papel de la administración forestal, como impulsora y organizadora de los aprovechamientos, so pena de que ésta se convierta en un recuerdo de algo que en su día tuvo sentido pero que, por mor de su incapacidad 
para adaptarse a las nuevas circunstancias, pase a ser una rémora en lugar de la punta de lanza de la gestión del medio forestal. Por supuesto, existen excepciones al papel excesivamente rígido y limitador de las administraciones: el Programa de movilización de los recursos forestales de Castilla y León es un ejemplo de cómo en ocasiones los poderes públicos toman la iniciativa (EZQUERRA et $a l ., 2013$ ).

El mundo forestal actual vive un momento de transformación profunda que la crisis actual ha acelerado enormemente. Pero no debemos confundir los efectos de la crisis económica de los años recientes con algunas cuestiones que la trascienden. Simplificando se podría decir que ha pasado el momento en que los montes españoles tenían cierta relevancia en la inversión pública, con esfuerzo máximo en relación a los recursos en la década de los años 50 del siglo XX y también muy elevado en el principio de los 80, para llegar a una situación en la que los montes ya se han recuperado suficientemente como para que empiecen a realizar una aportación decisiva en la economía. Otra cosa es que la crisis actual ha acelerado enormemente, de forma en absoluto planificada, una transición inevitable. De nosotros depende que el cambio sea menos traumático.

Los forestales hemos dependido siempre de los presupuestos públicos para nuestras actividades y hasta para la propia existencia como colectivo. Eso era lógico en la penosa situación de los montes durante el sistema agrario tradicional, pero ha llegado el momento de que, al menos donde las condiciones de explotación sean favorables, los montes financien su propia gestión. Hay que asumir, con carácter general, el fin de la "selvicultura de ricos" (la que se realiza sin importar la optimización del balance económico como un factor muy importante) y de la estética de jardín en los montes. Cada vez que enseñábamos a selvicultores extranjeros ejemplos de la selvicultura "de jardín" que tanto se ha practicado en España, los comentarios, variando según la persona concreta y la traducción que hacíamos, iban siempre en el mismo sentido: "España es rica". Desde luego eso obligaba a una reflexión por parte de los presentes que en el conjunto de los técnicos se justificaba siempre sobre la base de la "peculiaridad ibérica", que incluía algunas dosis del sacrosanto riesgo de incendios que todo lo ampara, incluso acciones que a medio plazo son contraproducentes (cuando se aclara en exceso y se favorece la proliferación del matorral), pero a corto dejan el monte "muy bonito".

En ningún sitio de Europa Occidental, y por supuesto en la inmensa mayoría del planeta, se ha practicado con el mismo entusiasmo la "selvicultura de ricos". Por ejemplo, se han efectuado carísimas extracciones de madera por empresas de trabajos selvícolas (en lugar de maderistas) solo porque las calles de desembosque "hacen feo" o por el "elevado impacto de la maquinaria pesada"; ese dinero, dilapidado durante la "bonanza económica", podría haberse invertido en infraestructura viaria que pudiese permitir indefinidamente aprovechamientos rentables. Se puede anunciar solemnemente que ¡la fiesta ha terminado! Que nadie piense que la situación es transitoria y cuando regrese el crecimiento económico volveremos al estado previo. El mundo cambia vertiginosamente y otros países reclaman su sitio en el mundo y sus ciudadanos mejorar sus condiciones de vida. Una reorganización es imprescindible, y en ella ya no deben tener cabida las inversiones innecesarias motivadas por prejuicios o comodidad.

El colectivo de los técnicos forestales españoles nació para hacer posible la supervivencia de los mejores montes, aquéllos que debían evitar que se vendiesen en los procesos de desamortización. En el siglo XX se avanzó desde el paradigma de la supervivencia al de la restauración forestal, mediante unos programas de repoblaciones casi sin referentes mundiales por su magnitud. Muchos de los macizos forestales de los que hoy disfrutamos son producto de esa ingente labor. El paradigma del siglo XXI, al menos tal como se percibe en sus albores, debería ser el del impulso de los aprovechamientos, entre otros objetivos para dar sentido a la labor realizada en los siglos precedentes logrando la plena funcionalidad de los montes salvaguardados y recuperados, dentro de lo que se incluiría la integración ecológica de las repoblaciones del siglo XX.

No tiene sentido que los recursos públicos paguen todo. Sí las inversiones precisas para iniciar el ciclo productivo forestal, que puede ser eterno; pero no en montes que podrían ser rentables con una gestión adecuada. Los prejuicios, la 
comodidad y la inercia hacen que muchas veces se gaste en actuaciones que podrían autofinanciarse con la organización y seguimiento adecuados. En los parques nacionales están prohibidas las cortas comerciales (y la caza), cuando para el cumplimiento de las funciones ecológicas pueden ser necesario cortar (o el control de poblaciones animales): si se gasta dinero público por la misma actuación, entonces sí es ético o lícito. Hay que cambiar la mentalidad exactamente en el sentido contrario: si una actuación se efectúa con dinero público tiene que estar mucho más justificada, y ser más la excepción que la regla. La inversión pública debe servir para poner en producción montes con productos de escaso valor que sin un empuje inicial no podrían gestionarse; no se puede concebir como un aporte perpetuo para mantener sistemas anacrónicos o para subvencionar (directa o subrepticiamente) a los propietarios de los montes.

Lo que vale para una época puede ser deletéreo en otras. Usar la capitalización de existencias como indicador de una buena gestión es razonable en un contexto de sobreexplotación, pero cuando los montes se usan muy por debajo de su capacidad productiva, la situación se invierte y nuestros paradigmas deberían modificarse en consecuencia. A la posibilidad de corta como un máximo que no debe superarse se debe contraponer, en las actuales circunstancias, la "necesidad de corta”, un mínimo que debería cortarse para que el bosque continuase cumpliendo, o empezase a cumplir, las funciones ecológicas, sociales y económicas que la sociedad espera de ellos.

Es importante tener clara la orientación general de la política forestal para poder establecer unas líneas prioritarias que deba seguir la investigación. Por ejemplo, si el objetivo fundamental fuese la restauración vegetal, como lo ha sido durante el siglo XX, se deberían desarrollar programas de evaluación del patrimonio genético, de mejora genética, de técnicas de implantación, etc. Teniendo en cuenta la situación actual de los montes españoles, así como el contexto

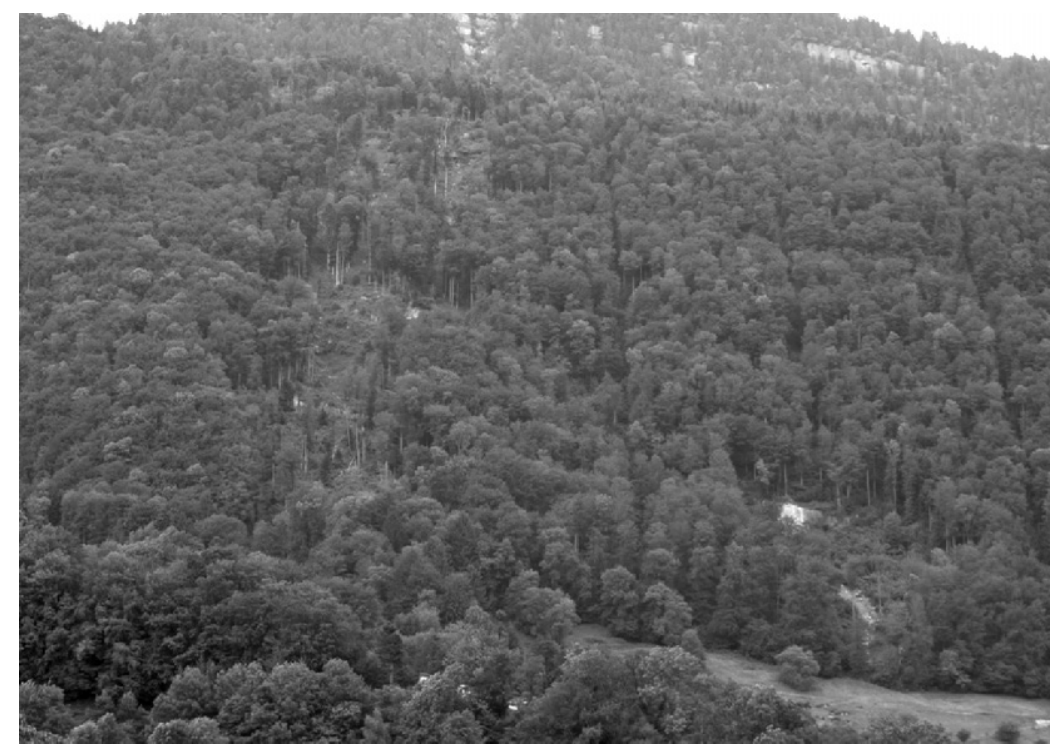

Figura 9. Bosque en elevada pendiente y terreno inestable en el que se aprecian las calles de desembosque de los aprovechamientos de madera. También se observan los efectos de intensas precipitaciones acaecidas 4 años antes de tomarse la imagen y que reactivaron antiguos procesos erosivos, mucho más intensos cuando el monte se encontraba deforestado, solo un siglo antes. Aquí se asume que para que los bosques continúen cumpliendo su función protectora, en especial en relación frente a aludes pero también otros riesgos, es necesario renovarlos, mediante cortas, en pequeños bosquetes. Como eso exige trabajar en pendientes que superan el 60\%, subvencionan el desembosque en bosques protectores en los que la explotación forestal tiene unos costes muy elevados. Es decir, la catalogación como bosque protector conlleva que se asume la necesidad de realizar cortas, casi lo inverso que en España (Weggis, Suiza) 
socioeconómico general, lo lógico es que la política sea ahora la del fomento de los aprovechamientos forestales de todo tipo, muy en particular de los de madera, pero también pastos, piñones, resina... Y ahí debería dirigirse la investigación en España: cómo lograr mayores producciones y de mejor calidad, búsqueda de productos novedosos, comprobación de que las técnicas usadas no conducen a efectos indeseables en el ecosistema, etc.

No son necesarios costosos estudios ecológi$\cos$ ni siquiera inventarios cuantitativos para aplicar la selvicultura que precisan de forma generalizada los bosques españoles: las claras. Ningún lugar del planeta se ha deforestado o se han extinguido sus especies asociadas por efectuar claras suaves o moderadas, que respetan el microclima forestal. En la medida en que las claras no utilicen la técnica de extracción del árbol completo, la ecología basada en el estudio de los ciclos de los elementos tampoco parece que pueda realizar contribuciones decisivas a este respecto: la madera que se extrae son compuestos carbonados con una proporción baja de nutrientes y oligoelementos, fácilmente reemplazables en un régimen de claras suaves. Con este tipo de selvicultura no son previsibles problemas por pérdida de diversidad (al contrario, en la situación actual de las masas) o de nutrientes (siempre que no se aprovechen las hojas y ramillas muy finas, algo que en general no se realiza por rentabilidad de las operaciones). La mayor prevención se centra en evitar la erosión, que se puede producir tanto en pistas forestales como en calles de desembosque. Para evitarlo se deben emplear un conjunto de técnicas que básicamente se resumen en no trabajar con maquinaria pesada sobre el suelo muy húmedo $\mathrm{y}$ procurar modificar lo menos posible el régimen hidrológico, evitando la concentración de aguas en puntos donde puedan producir erosión.

De la crisis podemos salir de dos formas: siendo más pobres o actuando más inteligentemente. Seguramente necesitemos ambas: usar más eficientemente nuestros recursos y potencialidades para evitar en la medida de lo posible que nuestro nivel de riqueza y bienestar caiga. Los precios actuales de los combustibles fósiles (y foráneos) para calefacción suponen una oportunidad histórica para los bosques españoles: posibilitan intervenir selvícolamente sobre grandes superficies obteniendo además unas rentas para sus propietarios.

Existe una normativa ambiental y una organización administrativa que han complicado tanto las explotaciones forestales en los espacios naturales protegidos (que son una parte sustancial de los mejores terrenos forestales) que, al menos en ciertas comunidades autónomas, desanima a casi cualquier propietario o gestor. Sin duda estas normas, y la interpretación todavía más restrictiva que se hace de ellas, no son ajenas a una visión catastrofista más o menos extendida entre los grupos ecologistas y que se ha difundido a la sociedad, según la cual cada vez hay menos y peores bosques, y hay que preservar a toda costa los escasos rincones prístinos de nuestra geografía. Esta visión se ha apoyado en las teorías y trabajos de una parte del sector científico español, en especial en algunos grupos dentro de universidades públicas, e incluso en buena parte de la normativa, incluida la que da amparo jurídico a la Red Natura.

A pesar de que en teoría está plenamente asumido por la comunidad científica que lo importante es la conservación de los procesos y no las cosas (TERRADAS, 1998), las perspectivas estáticas siguen estando muy presentes tanto entre científicos como entre gestores de espacios protegidos, y en su normativa. Además, se da con carácter general una preferencia apriorística por las dinámicas espontáneas, por mucho que éstas incluyan unas condiciones de partida muy poco naturales. Se da poco margen de opción para valorar de forma positiva las acciones del hombre (al menos las tecnificadas, con las tradicionales se es más indulgente); casi siempre se interpreta esa acción humana en términos de "degradación", en lugar de analizar si ha servido para cumplir objetivos o no. Probablemente, en la base de esta visión, que está exacerbada respecto a otros países europeos, se encuentra el hecho de que en España el fin del sistema agrario tradicional sobrevino de forma muy brusca y radical, pasando de una situación de subdesarrollo crónico del agro (respecto a los estándares de Europa Occidental) a otra en la que la modernidad deslumbraba con sus adelantos. Esa tardía revolución se produjo cuando ya existía un notable adelanto tecnológico y explica, por ejemplo, 
el uso generalizado del bulldozer para hacer terrazas en las repoblaciones, independientemente de las condiciones del monte. Los campesinos y ganaderos españoles de finales de los 50, 60 y 70 del siglo XX, hartos de las penurias de sus antepasados y de las suyas propias, abrazaron con inusitado fervor una modernidad que se les antojaba remediadora de todos los problemas. El retraso secular dio paso a abandonar todo lo viejo, incluyendo un patrimonio tan valioso como el de las razas y variedades surgidas mediante mejora genética aplicada durante milenios y perdida en sólo dos décadas. La desconexión entre la sociedad y el medio en el que vive es en España mucho mayor que en países como Francia. En este contexto se entiende mejor esa aversión por la intervención en un medio que ahora no se comprende.

Teniendo en cuenta que en España los espacios naturales protegidos y la Red Natura abarcan grandes extensiones, no tiene sentido que sus montes se gestionen de forma muy distinta a los del resto del territorio: a diferencia de la agricultura, donde se ha generalizado una forma de manejo muy poco ecológica, con grandes dosis de herbicidas y fitosanitarios, en la mayoría de los montes (con excepción de buena parte de las plantaciones de exóticas) la gestión es mucho menos agresiva, más respetuosa con el entorno y que aprovecha en mayor medida las dinámicas espontáneas. Fuera y dentro de los lugares protegidos se debe actuar con semejantes cautelas. Si acaso, la Red Natura, al imponer la conservación de ecosistemas pioneros, exigirá en ciertos casos actuaciones más contundentes que donde no existe esa obligación legal. El principio de precaución, que implica entre otras cautelas evitar erosión y pérdidas genéticas, se debe aplicar en todos los montes por igual. La técnica de dirigir los procesos mediante aprovechamientos, también. En los países que han optado por espacios naturales de reducido tamaño, o en aquellos otros que todavía conservan grandes ecosistemas prístinos (sobre todo en América), el planteamiento puede ser muy diferente al expuesto en este párrafo.

El discurso ecologista, y sobre todo algunas acciones (en los medios de comunicación y en los juzgados), han favorecido que las administraciones forestales prefieran evitar las cortas que pro- moverlas. Para el funcionario la inactividad raramente está castigada, mientras que la iniciativa genera muchos problemas. Además, en muchos casos, los propios profesionales, que han dejado de intervenir en los montes más allá de acciones puramente estéticas, han perdido la capacidad de predicción de cómo responde el monte en cada circunstancia concreta, y al final han acabado por abrazar postulados ecológicos en los que cada intervención se ve como injerencia en el "orden natural". Cuando se abre un abismo entre las necesidades de gestión para cumplir los objetivos y las capacidades de los actores, se llega a una situación sumamente peligrosa, puesto que cuando finalmente se interviene en el monte, se hace a remolque de los acontecimientos, normalmente cuando la situación se ha ido de las manos (por ejemplo por bosques muy inestables frente a derribos, incendios reiterados, poblaciones de ungulados desbocadas, propietarios enfadados por las limitaciones, etc.) y se actúa sin el bagaje previo de las acciones preventivas, normalmente moderadas. La falta de perspectiva a largo plazo y de conocimientos, tanto teóricos como sobre todo prácticos (experiencias previas, ensayo y error), lleva tanto a la ausencia de intervención como al no respeto a las reglas ecológicas básicas cuando las necesidades apremian.

Existen prejuicios contra las cortas, las pistas forestales, el uso de maquinaria pesada, de maquinaria en general frente al trabajo manual, de coníferas frente a frondosas, de preferencia irreflexiva por lo ancestral; cierto es que es difícil de superar el encanto de algunos paisajes generados por los usos tradicionales, y que se han cometido no pocos desmanes en explotaciones forestales, pero hoy en día existen los medios para evitarlos, y ante las dificultades la peor solución es la parálisis. Los prejuicios terminan por generar comportamientos aberrantes: por ejemplo, cuando la tozuda realidad acaba imponiendo el uso de maquinaria, se carece de la experiencia necesaria para usarla eludiendo daños al suelo y al arbolado remanente, y éstos finalmente se toleran como inevitables. La disociación entre ecología y economía, y entre los puntos de vista urbano y rural, éste último mucho más preocupado por aprovechar sus recursos, es otro enfoque del mismo tema. Tarde o temprano, las necesidades económicas 


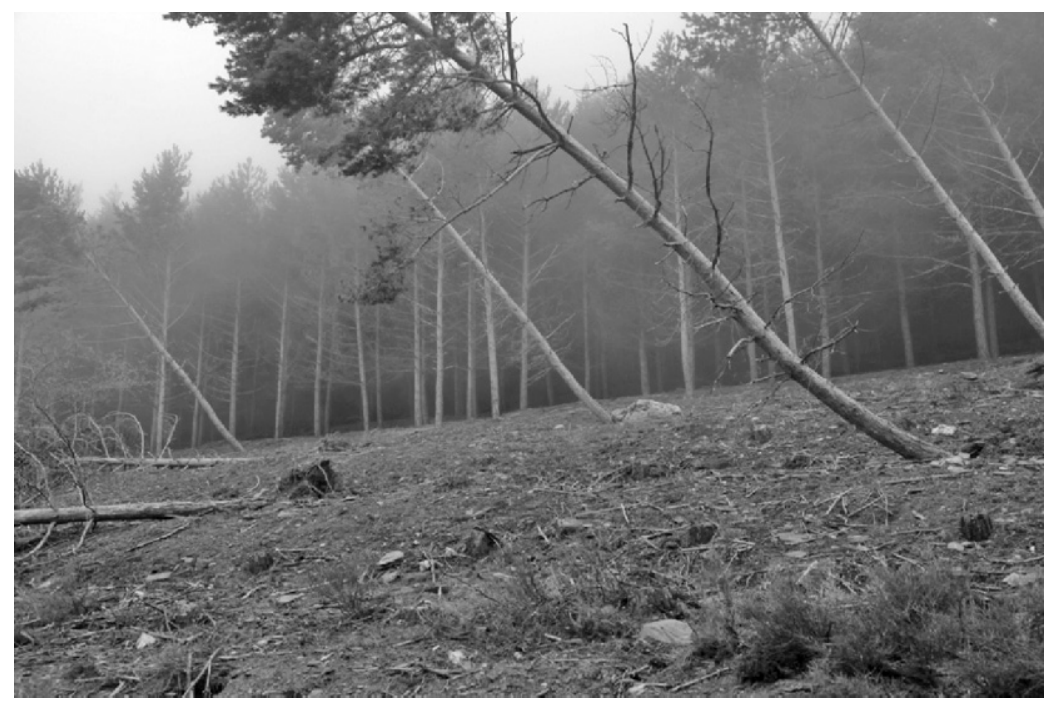

Figura 10. Faja auxiliar al borde de pista forestal. Detrás de la faja se observa un límite brusco con una repoblación excesivamente densa y extensa. En lugar de reducir progresivamente la espesura en el conjunto del rodal se ha optado por una acción drástica en una faja a ambos lados de la pista. La gran liberación de espacio vegetativo será aprovechada por vegetación de menor talla, que a medio plazo incrementará el riesgo de incendio forestal. Los derribos son mucho más probables con reducciones tan súbitas de la espesura. Hoy día, con la adecuada organización, las condiciones de mercado permitirían realizar el tratamiento del conjunto de la masa autofinanciado, mejorando la vitalidad de los pies remanentes y la estabilidad del bosque (Laroles, Granada)

acaban siendo en algún momento apremiantes, y si no se tiene suficientemente organizado el aprovechamiento racional de los recursos, es fácil exceder los límites que una gestión experimentada no sobrepasaría: la gestión de los ecosistemas no es sencilla, no se improvisa, y en ella el ensayo y error juega un papel crucial. Los prejuicios están tan extendidos en la sociedad que inevitablemente terminan por afectar, en diferentes grados según la persona y la presión social de su entorno, a los profesionales. Maderistas, ingenieros y otros forestales es muy probable que se vean, en algún momento de su vida, teniendo que explicar a sus hijos que sus padres no son delincuentes o inmorales por cortar árboles. Hasta que no se asuma que los aprovechamientos son la base de las políticas de conservación, la posición de los forestales será muy frágil.

En muchas comunidades autónomas españolas, los recientes años de bonanza económica han sido años perdidos en cuanto a establecer las bases de un aprovechamiento sostenible y de futuro de los montes. En los dos primeros ter- cios del siglo XX, en unas condiciones económicas incomparablemente más penosas, se abordaron trabajos forestales e inversiones de futuro que no se han acometido en las décadas recientes. La visión cortoplacista de nuestros políticos, que no deja de ser la de nuestra sociedad, es la culpable de este fracaso histórico. Seguramente no seamos peores que hace 50 ó 100 años, pero entonces había minorías ilustradas con visión de futuro y que eran conscientes de la importancia estratégica de los aprovechamientos forestales. En una sociedad moderna y democrática esto sólo se puede lograr mediante una cultura forestal que empape toda la sociedad: ya no es suficiente con que unos pocos sean conscientes del camino a seguir. Pero la cultura de la información fácil de comunicar e impactista se ha impuesto, dejando poco margen para análisis profundos.

La idea de que la madera cumple, con carácter general una función ecológica más importante si no se extrae del monte sólo puede emanar del prejuicio de la no intervención, de la naturaleza intocada, algo absolutamente ajeno a la rea- 
lidad ibérica y europea: los ecosistemas españoles se han desarrollado, e incluso han evolucionado, bajo una presión de aprovechamiento muy superior a la actual, como formaciones abiertas y con árboles maltrechos debido a las cortas, incendios, pastoreo, esquilmo... Hoy en día, para que los bosques continúen prestando algunos de los más importantes servicios ecológicos (defensa frente a la erosión, hábitat para la fauna y otros seres vivos) y para mejorar su estabilidad (frente a incendios o derribos) es muy necesario que se vayan aclarando. En mi opinión lo más adecuado serían con carácter general frecuentes claras altas de baja o moderada intensidad (20$25 \%$ en volumen) a favor de los pies de más calidad, aunque lógicamente de forma adaptada a las peculiaridades locales. La moderación en las cortas, entre otros efectos, previene derribos masivos, mantiene el microclima, evita la proliferación del matorral colonizador (pirófito). La frecuencia elevada es lógica consecuencia de la baja intensidad y además ayuda al mantenimiento de la red viaria. En todo caso, el debate acerca del tipo preciso de claras es secundario frente a su imperiosa necesidad en todo tipo de bosques, en especial en el norte los poblados por frondosas nativas (ver algunos datos al respecto en Sevilla et $a l ., 2013$ ) y en pinares de toda España.

\section{LA GESTIÓN DEBE TENER LA INICIATIVA EN LA DINÁMICA ECOLÓGICA}

El conocimiento predictivo (las teorías en el sentido de Peters) debe ser la base para el desarrollo de modelos ecológicos realistas que sirvan para una gestión orientada a cumplir objetivos explícitos y no difusos. El enfoque de las series de vegetación, a pesar de su indiscutible éxito académico y de su amplia mención en los estudios forestales, es muy poco práctico para la toma de decisiones. Se ha convertido en una especie de mantra que se cita por costumbre.

La predicción ecológica es muy compleja, pero las alternativas de gestión son suficientemente limitadas como para que en general el proceso de toma de decisiones no se convierta en inabordable. $\mathrm{Si}$ asumimos que el dinero público apenas va a fluir hacia los montes, la principal decisión, en un rodal arbolado concreto, será si cortar o no, y cómo y cuándo, y la red viaria asociada (lo que no es poco, pero es abordable). Además, en la situación actual de los bosques españoles, con una gran superficie cubierta de latizales y fustales jóvenes, la decisión sobre el tipo de cortas va a ser muy frecuentemente hacer claras. En algunos lugares serán precisas cortas de regeneración, aunque en general se trata de grandes macizos forestales donde los profesionales locales (y los lugareños) han acumulado un bagaje de conocimientos con el que enfrentarse a este tipo de trabajos, siempre que se esté atento a los cambios de condiciones y se esté dispuesto a adaptar los métodos. Otro grupo de decisiones trascendentales son las relativas al manejo ganadero y de la fauna silvestre (pastar o no; reducir poblaciones de animales silvestres o no; siempre con múltiples variantes sobre cómo, dónde y cuándo hacerlo). El resumen podría ser que la gestión consiste en aprovechar el monte de una determinada forma para conseguir simultáneamente una serie de objetivos. Evidentemente será preciso adoptar otras muchas decisiones, pero en general serán menos relevantes o afectarán a superficies más reducidas (por ejemplo, la recuperación de terrenos erosionados o contaminados). En todo caso, la complejidad nunca debe ser paralizante. Habría que aplicar el aforismo de "en la duda actuar (aprovechar: cortar o pastar), siempre que no se aboque a procesos indeseables y difícilmente reversibles". Esto último es fácil de evitar si, hasta que se reúna suficiente experiencia en un contexto ecológico concreto, se opta por intervenciones poco intensas.

En cierto modo se podría decir que la generación actual de forestales es afortunada porque ha llegado en el momento de "cosechar" los frutos del trabajo de las anteriores generaciones, y porque en lugar de tener que luchar contra una sociedad necesitada de todo tipo de bienes materiales, para evitar la sobreexplotación, ahora puede contribuir a la mejora de la economía a través de un aprovechamiento racional de los montes. Pero en los bosques la "cosecha" juega un papel mucho más fundamental que la mera recogida de beneficios: es el instrumento a través del cual se conforman los ecosistemas 


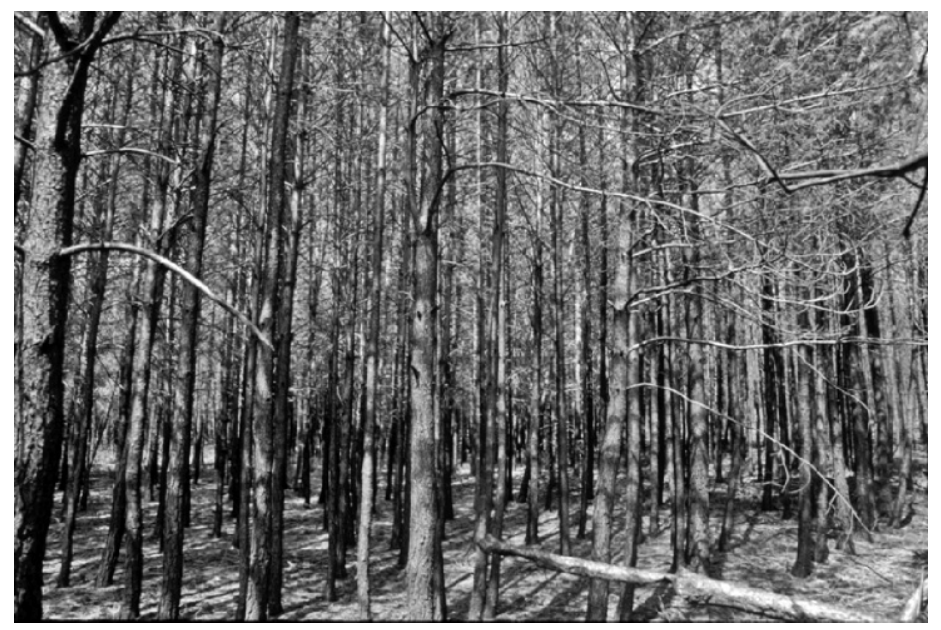

Figura 11. Pinar de pino silvestre muy denso quemado. Debería haber sido objeto de clara unos años antes del incendio, no tanto por el cambio de estructura en relación a los incendios forestales como por el hecho de haber proporcionado ingresos a la entidad propietaria, que hasta el momento había percibido más perjuicios que beneficios por la repoblación. Es sumamente peligroso caer en el ciclo de que se corta sólo cuando se quema, en especial en comarcas donde esté asentado el uso del fuego entre la población rural (Valcuende, León)

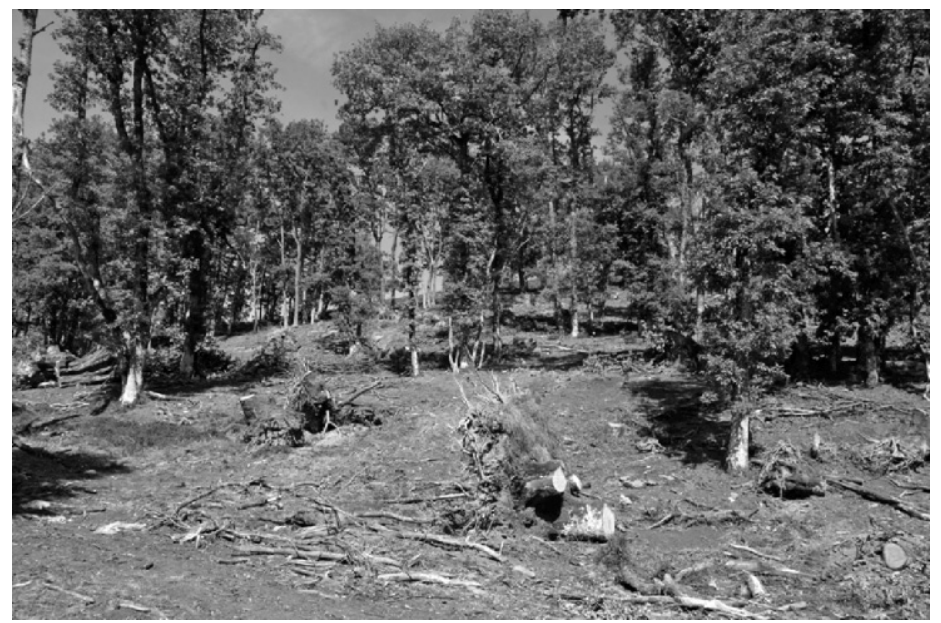

Figura 12. Robledal de Q. petraea en el que ha acaecido un derribo en masa (nivel de rodal, es decir, del orden de las hectáreas). Se acaba de aprovechar la madera de los árboles desarraigados. No se habían realizado cortas al menos en los últimos 70 años. Con anterioridad había sido intensamente explotado como prueban la multitud de carboneras dispersas en él y un estrato de madroños que va desapareciendo debido a la intensa concurrencia con los robles: es un remanente de épocas en las que el monte estaba mucho más abierto. El hecho de que el rodal sea regular hace pensar que el abandono de los aprovechamientos fue brusco, y se dio lugar a una generación de robles bastante coetánea, que es la que ahora domina. La calidad de estación es magnífica y, con la selvicultura adecuada, permitiría obtener madera de la mejor calidad, incluido el destino de cubas de vino. Pero no se han efectuado claras (excepto la espontánea, por el viento), y tras el derribo los árboles remanentes se han llenado de brotes epicórmicos, con lo que su madera se ha depreciado ostensiblemente. Esperar a que haya derribos para realizar las cortas conlleva malvender la madera (explotación difícil y peligrosa; no se puede elegir el momento ni el tipo de producto que se ofrece). Además, las pistas se acaban abriendo para acceder al rodal derribado y no pensando en una gestión global del monte. Los inconvenientes de ir a remolque son evidentes (Gijano, Burgos) 


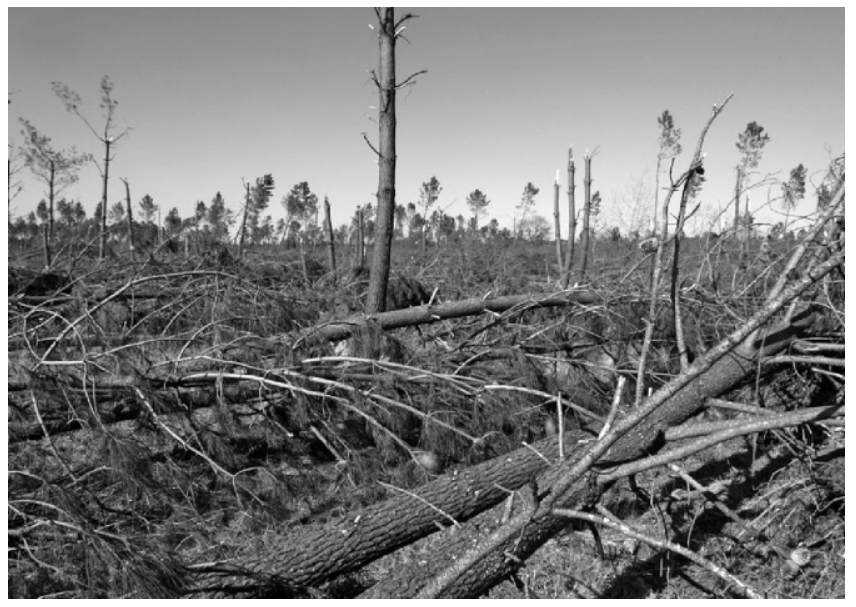

Figura 13. Extensos derribos en Las Landas. Como consecuencia de la intensa borrasca Klaus se vio afectada una superficie superior de 200.000 ha con unos 40 millones de $\mathrm{m}^{3}$ derribados. Por el momento estas cifras resultan casi impensables para España, pero la rápida capitalización de existencias y los insuficientes trabajos selvícolas hacen que en un futuro cercano se puedan dar en las comarcas donde los incendios no se prodigan. En todo caso, la monoespecificidad y excesiva homogeneidad de los pinares landeses son factores de fragilidad (Mont-de-Marsan, Francia).

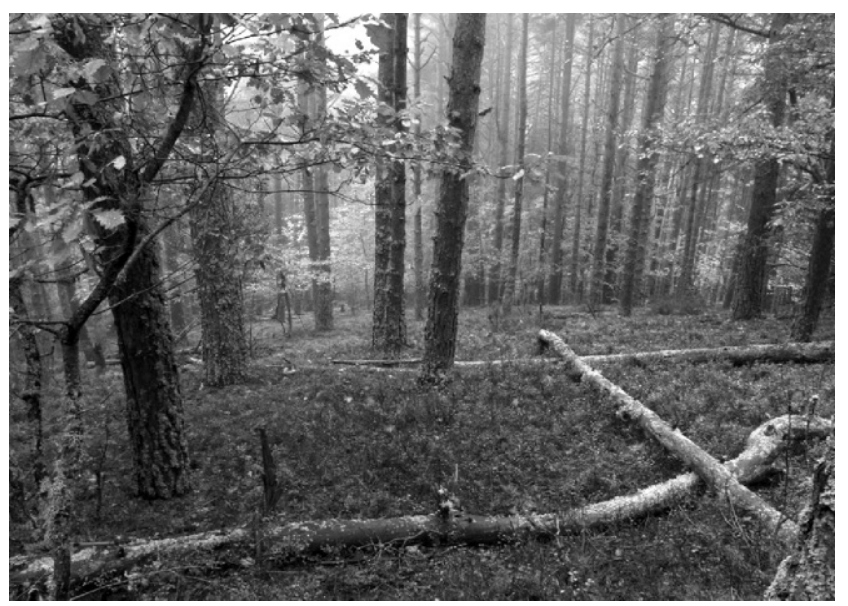

Figura 14. Repoblación de pino silvestre de casi un siglo de edad. Del brezal original sobre el que se instaló apenas quedan unos pocos individuos y muchos palos secos. El sotobosque ha sido sustituido completamente por arándano (Vaccinium myrtillus). Prolifera la regeneración anticipada de frondosas, sobre todo de roble, pero también de haya, serbal (Sorbus aucuparia), mostajo, avellano, olmo (Ulmus glabra, de forma esporádica) y acebo. Los derribos de pequeña extensión y la muerte en pie de pinos dispersos van liberando algo de espacio vegetativo. El lugar constituiría un hábitat idóneo para el urogallo si no fuese por un detalle que resulta decisivo: se observa cómo las frondosas instaladas bajo el pinar no tienen follaje por debajo de dos metros. La acción de fitófagos de gran tamaño, en concreto aquí ciervos, elimina la parte baja de las copas de los árboles, pero además casi imposibilita la instalación de nuevos individuos: la profusa regeneración anticipada no hubiese existido con las densidades actuales de ciervos; es una herencia del pasado, como la plantación de pinos. Pero además, el aumento de ciervos ha ido parejo al de otros animales con potenciales efectos negativos sobre las puestas y los pollos de urogallo, como jabalíes, mustélidos y rapaces. El resultado conjunto de mayor visibilidad por el ramoneo del ciervo y del efecto directo de los predadores está resultando letal para el urogallo, a pesar de que los bosques se hayan extendido. La imagen resume dos procesos que se están produciendo aceleradamente en los montes españoles: aumento de existencias y de animales silvestres, en ambos casos de forma descontrolada y, para muchos objetivos, excesiva (Boca de Huérgano, León) 


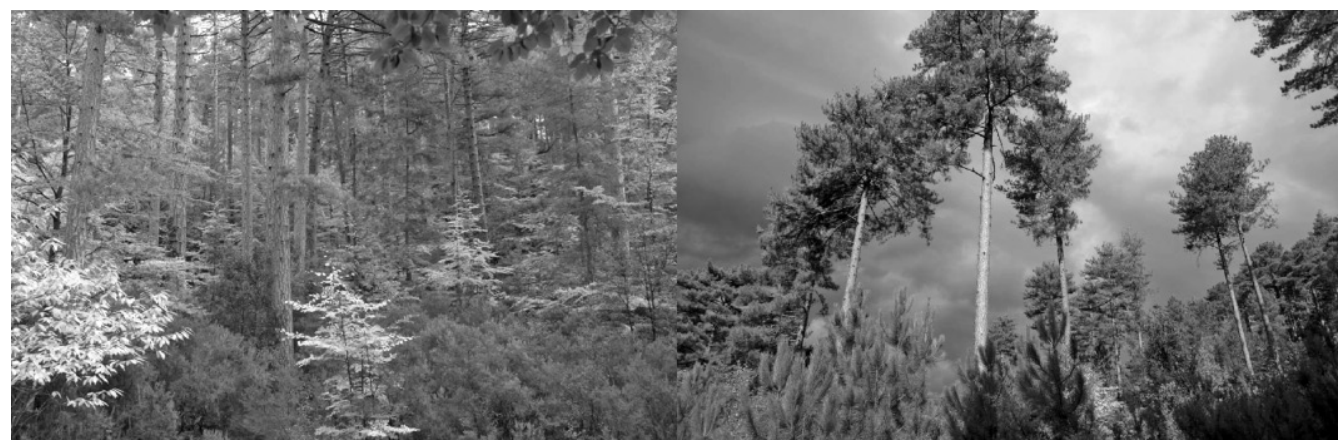

Figura 15. Rodal boscoso cuya dinámica podría parecer difícil de modelizar teniendo en cuenta la gran variedad de especies vegetales que intervienen decisivamente. Se trata de un pinar dominado en este bosquete por Pinus nigra y en otros contiguos por Pinus pinaster. Bajo los pinos se presenta un estrato de brezos (Erica arborea) y abundante regeneración anticipada de frondosas (aquí haya, castaño y encina, pero varias más en las proximidades) y algún pie ocasional de pino. Sin mediar eventos renovadores el haya impondría su dominio en el subpiso, por su tolerancia y abundancia (mayores que el castaño y otras frondosas presentes) y velocidad de crecimiento en altura (muy superior a la encina), pero Pinus nigra es especie de longeva y dominaría el dosel superior durante siglos; los brezos sucumbirán con relativa rapidez porque su escasa tolerancia le permite sobrevivir bajo un dosel elevado de pino, pero no bajo un subpiso cerrado de haya. Un fuego destructivo favorecería a las especies consideradas pirófitas (Erica arborea y Pinus pinaster), que se regenerarían respectivamente por brote (sin incertidumbre) y semilla (con las incertidumbres típicas de los procesos de regeneración por semilla, bien conocidos por los forestales y muy variables según las precisas condiciones locales), pero también a las encinas, extremadamente resilientes y con pocas opciones si no se eliminan las hayas. Mediante cortas, en función de cómo se ejecutasen, sería sencillo promocionar a cualquier especie que interesase: lo más fácil sería lograr el dominio del haya, pero se podría promover el de castaños y encinas, eliminando la concurrencia con hayas y pinos, e incluso el mantenimiento a largo plazo del pinar, mediante cortas intensas, como se ha efectuado en el bosquete de la imagen de la derecha. En realidad es relativamente sencillo efectuar predicciones de tipo cualitativo, lo que es suficiente para la toma de muchas decisiones de gestión pero no optimiza los objetivos, algo que para lograrse debería recurrir al desarrollo cuantitativo de los modelos de sistemas complejos (Vizzavona, Córcega, Francia)

para que cumplan los servicios que de ellos se esperan. Los aprovechamientos, en la teoría de sistemas complejos, juegan el papel de esos eventos suaves o moderados que dirigen la trayectoria hacia donde se prevé un mejor cumplimiento de objetivos y que previenen otros eventos de mayor intensidad. Son el instrumento para lograr una relativa constancia y la conservación de los atributos esenciales de los ecosistemas en la conocida como "paradoja multiescalar": para mantener una cierta constancia a un determinado nivel es necesario implementar cambios a un nivel inferior. Idea que por otra parte está presente en la clásica ordenación de montes: corta de árboles individuales (entresaca) para que el rodal permanezca semejante a sí mismo en el tiempo; corta de rodales para que lo haga el monte.

En sistemas complejos las relaciones no lineales son la norma, lo que se debe tener muy presente en su estudio y por supuesto evitar las proyecciones lineales de hechos pasados, algo que por ejemplo se ha hecho con sorprendente falta de autocrítica en algunas proyecciones del clima futuro. En los montes el cambio en las dinámicas es la norma. Es importante estar preparados y asumir con normalidad transformaciones profundas que afectan no sólo a todos los componentes del ecosistema sino también a las relaciones entre ellos, lo que exige nuevos planteamientos en la gestión, en los paradigmas dominantes y en la forma de enfocar los análisis. Por ejemplo, hace sólo unas décadas parecería imposible que ahora fuese un problema el exceso de capitalización de los bosques o la abundancia de animales como ciervos o jabalíes, hasta el punto de alterar la estructura forestal, los procesos de regeneración e incluso comprometer la supervivencia de especies como el urogallo.

No existen alternativas de gestión que maximicen los beneficios para todos los grupos de seres vivos. Es necesario asumir que cualquier decisión va a conllevar mejores condiciones para unos en detrimento de otros. En principio 


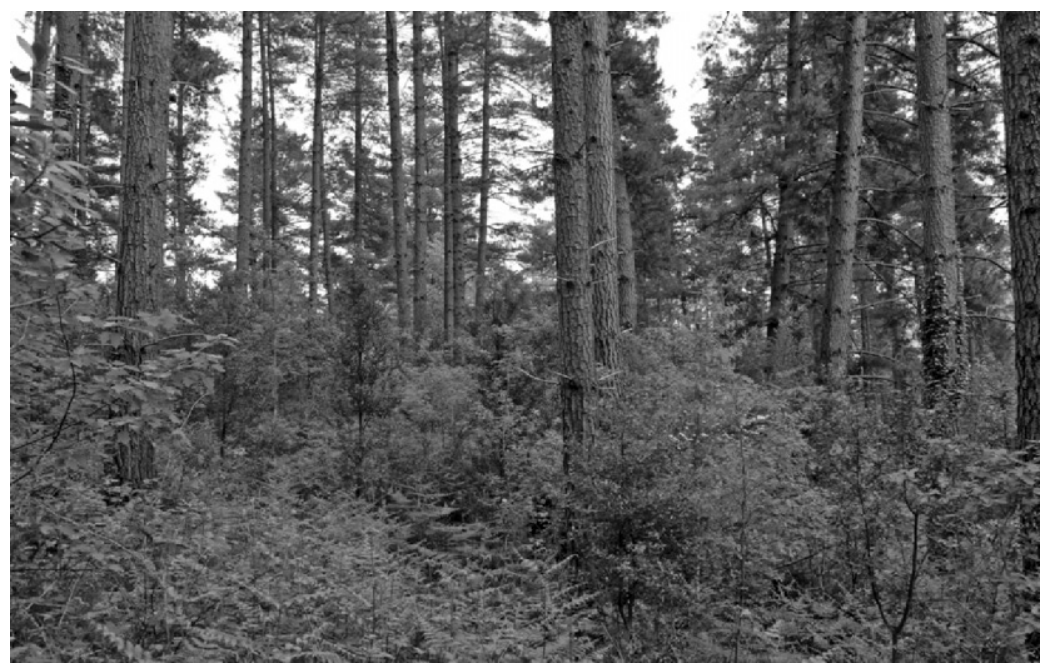

Figura 16. La naturaleza nos enseña a ser flexibles en la gestión, incluso oportunistas. La imagen corresponde a un pinar de $P$. radiata en el que, tras tres claras, se ha instalado una abundante regeneración anticipada de varias especies de frondosas (Quercus robur, Q. ilex, Castanea sativa, Sorbus torminalis, Sorbus aria), y algún pino (P. radiata) disperso. También hay madroños en el subpiso, con un significado dinámico y unas opciones futuras de desarrollo muy diferentes de las frondosas, ya que se trata de un arbusto que no puede alcanzar su talla. Aunque era previsible que en la fase de reposición se instalasen frondosas, lo cierto es que las fuentes de semilla no estaban en el rodal (excepto el castaño) y fueron diversos animales silvestres los que llevaron las semillas (las bellotas sobre todo los arrendajos). Existía una notable incertidumbre sobre el alcance, variedad y distribución de los árboles instalados, y ni el proceso de regeneración espontánea ni el posible cambio de especie estaban previstos en el proyecto de ordenación (se preveía corta a hecho y posterior repoblación). Pero el forestal debe estar atento a dinámicas imprevistas y aprovecharlas. La constancia de rentas (o la de cortas, o en general de extracciones en un ecosistema) es una quimera que forma parte del mismo mundo conceptual que la estabilidad en los ecosistemas, la idea de equilibrio ecológico o la de clímax: el cambio es la norma y la constancia que en muchos aspectos parecemos precisar los seres humanos debería circunscribirse a lo imprescindible: un cierto nivel de estrés y de cambio inesperado es deseable para mejorar nuestras capacidades (TALEB, 2012). Aquí el reto está ahora en ejecutar una explotación cuidadosa de los grandes pinos que permita aprovechar esta regeneración sobrevenida (Nava de Mena, Burgos)

no hay organismos mejores que otros, pero los humanos establecemos nuestra escala de valores en función de nuestras convicciones e intereses. La gestión y la investigación buscan compromisos entre la necesidad de simplificar y la de no obviar nada trascendente, lo que constituye un delicado equilibrio por la limitación de tiempo y recursos.

Debemos acabar con la gestión improvisada, a remolque de los acontecimientos, a la defensiva. Cuando en un monte se diseña e implementa la forma en que se producen las renovaciones, fundamentalmente a través de aprovechamientos, el seguimiento no exige costosos inventarios: si no sobrevienen eventos importantes e imprevistos, el desarrollo tras una renovación controlada es relativamente fácil de prever si se cuenta con experiencia previa en ese tipo de ges- tión. En términos dasocráticos sería una ordenación continua que no exigiría las clásicas revisiones ni sus inventarios asociados, sino un seguimiento continuo en términos cualitativos. La información cuantitativa se obtendría con ocasión de cada aprovechamiento: sería conocer al monte por sus flujos y no por su estructura.

\section{CONCLUSIONES}

La situación forestal actual española está llena de dificultades, retos y posibilidades. No existe una política forestal española, y las comunidades autónomas carecen en general del rumbo y los ritmos necesarios. En estas circunstancias, la indispensable adaptación a las nuevas circunstancias se efectuará con un retraso que no 
permitirá aprovechar las potencialidades. No obstante, algunos avances científicos e iniciativas de gestión son esperanzadores.

En los años 60 del siglo XX ha tenido lugar una revolución socioeconómica, que ha implicado profundos cambios en las dinámicas ecológicas. Sin embargo, los paradigmas forestales no han variado sustancialmente desde su origen, desde la respuesta defensiva frente a una explotación excesiva. Y a pesar de que hoy en día el problema de los montes es más su abandono que la presión para aprovecharlos, la ideología forestal no ha cambiado en consonancia.

La ciencia ha desarrollado unas formas novedosas de comprender el funcionamiento de sistemas complejos como son los ecosistemas forestales, basadas en la teoría del caos. Esta aproximación resulta más realista que otras en las que tienen excesivo peso ideas preconcebidas acerca de las rutas ecológicas. Estas ideas simplificadas han recibido una buena acogida en la sociedad española que se ha vuelto urbana y ajena a la gestión del monte: los sistemas complejos son mucho menos sugerentes que la idea de unos ecosistemas prístinos en armonía con una sociedad tradicional que los conservaba hasta que la modernidad (en forma de forestales actuando) perturbó el equilibrio. Se ha impuesto socialmente un paradigma de conservación en el que la no actuación es vista como la opción más deseable, y la explotación forestal como "mal necesario" para satisfacer el economicismo imperante. Sin embargo, con los conocimientos técnicos y ecológicos adecuados, las cortas y otros aprovechamientos son instrumentos decisivos para lograr una gran variedad de objetivos, incluidos los de conservación. Una capacidad de predicción mejorada, fruto de la integración entre ciencia y técnica, es el fundamento de una gestión anticipadora que aproveche las inmensas potencialidades de los montes españoles.

\section{Agradecimientos}

A Francisco Javier Ezquerra Boticario, por su revisión crítica que ha influido en aspectos esenciales del texto. A Juan Ignacio García Viñas, por sus aportaciones.

\section{BIBLIOGRAFÍA}

CARrión, J.S.; 2003. Sobresaltos en el bosque mediterráneo: incidencia de las perturbaciones observables en una escala paleoecológica. Ecosistemas 3/2003. URL: http://www.revistaecosistemas.net/index.ph p/ecosistemas/article/view/225.

CARRIÓN, J.S. (coord.); 2012. Paleoflora y paleovegetación de la Península Ibérica e Islas Baleares: Plioceno-Cuaternario. Ministerio de Economía y Competitividad. MadridUniversidad de Murcia. Murcia.

Diamond, J.; 2005. Collapse: How Societies Choose to Fail or Succeed. Viking. New York.

EZquerra Boticario F.J.; Rubio GutiéRrez, R., Picardo Nieto, A. \& Sánchez MARTíneZ, A.; 2013. Programa de movilización de los recursos forestales de Castilla y León. En: Actas del $6^{\circ}$ Congreso Forestal Español. S.E.C.F. Vitoria.

LORENZ, E.N.; 1963. Deterministic non-periodic flow. J. Atmosph. Sci. 20: 130-141.

MARGAlEF, R.; 1991. Teoría de los sistemas ecológicos. Publicacions de la Universitat de Barcelona. Barcelona.

OldEMAn, R.A.A.; 1990. Forests: Elements of Silvology. Springer. Berlin.

Peters, R.H.; 1991. A critique for ecology. Cambridge University Press. Cambridge.

RIvas-MarTínez, S.; 2011. Mapa de series, geoseries y geopermaseries de vegetación de España. Itinera Geobotanica. 18(1): 1-428.

SEvilla, F.; 2008. Una teoría ecológica para los montes ibéricos. IRMA. León.

Sevilla, F; Trassierra, A. y SABín, P.; 2013. Las cortas en los montes cantábricos: evolución, tendencias y perspectivas. En: Actas del $6^{\circ}$ Congreso Forestal Español. S.E.C.F. Vitoria.

Taleb, N.N.; 2012. Antifragile: Things That Gain From Disorder. Random House (US) \& Penguin (UK).

Terradas J.; 1998. Dinámica de los ecosistemas forestales mediterráneos. En: J.M. González-Molina (coord.), La gestión sostenible de los bosques: 17-28. Centre Tecnològic Forestal del Solsonès. Solsona. 